\title{
Genomewide Analysis of Rat Barrel Cortex Reveals Time- and Layer-Specific mRNA Expression Changes Related to Experience-Dependent Plasticity
}

\author{
Astrid Vallès, ${ }^{1,2}$ Arjen J. Boender, ${ }^{2}$ Steef Gijsbers, ${ }^{2}$ Roy A. M. Haast, ${ }^{2}$ Gerard J. M. Martens, ${ }^{2 \star}$ and Peter de Weerd ${ }^{1 \star}$ \\ ${ }^{1}$ Department of Neurocognition, Faculty of Psychology and Neurosciences, Maastricht University, 6200 MD Maastricht, The Netherlands, and ${ }^{2}$ Department \\ of Molecular Animal Physiology, Radboud University Nijmegen, Donders Institute for Brain, Cognition, and Behaviour (Centre for Neuroscience), \\ Nijmegen Centre for Molecular Life Sciences, 6525 GA Nijmegen, The Netherlands
}

Because of its anatomical organization, the rodent whisker-to-barrel system is an ideal model to study experience-dependent plasticity. Manipulation of sensory input causes changes in the properties of the barrels at the physiological, structural, and functional levels. However, much less is known about the molecular events underlying these changes. To explore such molecular events, we have used a genomewide approach to identify key genes and molecular pathways involved in experience-induced plasticity in the barrel cortex of adult rats. Given the natural tendency of rats to explore novel objects, exposure to an enriched environment (EE) was used to stimulate the activity of the whisker-to-barrel cortex in vivo. Microarray analysis at two different time points after EE revealed differential expression of genes encoding transcription factors, including nuclear receptors, as well as of genes involved in the regulation of synaptic plasticity, cell differentiation, metabolism, and, surprisingly, blood vessel morphogenesis. These expression differences reflect changes in somatosensory information processing because unilateral whisker clipping showed EE-induced differential expression patterns in the spared versus deprived barrel cortex. Finally, in situ hybridization revealed cortical layer patterns specific for each selected gene. Together, the present study offers the first genomewide exploration of the key genes regulated by somatosensory stimulation in the barrel cortex and thus provides a solid experimental framework for future in-depth analysis of the mechanisms underlying experience-dependent plasticity.

\section{Introduction}

Experience-dependent plasticity enables organisms to adapt their behavior to the environment. However, how experience shapes the functional organization of different brain systems is still poorly understood. At the level of sensory systems, the rodent primary somatosensory cortex (S1) is a particularly suited model to investigate the mechanisms underlying experience-dependent plasticity (Feldman and Brecht, 2005). The whisker-to-barrel system plays an important role in various types of rodent behavior, from foraging to object recognition (Brecht, 2007; Diamond et al., 2008). Its organization allows for the precise characterization of experience-dependent plasticity, thanks to the one-to-one correspondence of each whisker to its cortical receptive field in layer 4 of S1, the "barrel" (Woolsey and Van der Loos, 1970). In the barrel cortex, plasticity can be induced by modifying sensory input through simple manipulations, such as exposure to enriched environment (EE) or whisker clipping (Fox, 2002; Polley et al., 2004).

Received Dec. 14, 2010; revised Jan. 26, 2011; accepted Feb. 26, 2011.

This research was supported by VICI Grant 453_04_002 from the Netherlands Foundation of Scientific Research (P.d.W.). We thank Dr. Freddy de Bree for his valuable help with the bioinformatic analysis.

${ }^{*}$ G.J.M.M. and P.d.W. contributed equally to this work.

Correspondence should be addressed to Peter de Weerd, Department of Neurocognition, Faculty of Psychology and Neurosciences, Maastricht University, P.0. Box 616, 6200 MD Maastricht, The Netherlands. E-mail: p.deweerd@maastrichtuniversity.nl.

DOI:10.1523/JNEUROSCI.6514-10.2011

Copyright $\odot 2011$ the authors $\quad 0270-6474 / 11 / 316140-19 \$ 15.00 / 0$
Because of its easy accessibility, the whisker-to-barrel system is an ideal model to integrate a wide range of experimental approaches to dissect plasticity mechanisms at different levels, such as genetics, molecular biology, electrophysiology, and imaging (Brecht et al., 2004; Schubert et al., 2007; Petersen, 2009). Most studies investigating experience-dependent plasticity in barrel cortex make use of electrophysiological methods (Petersen, 2007). More recently, gene targeting and viral vector strategies have also been applied, permitting layer- and column-specific manipulation of the expression of selected genes to study their function (Aronoff and Petersen, 2008), visualization of structural plasticity (Knott and Holtmaat, 2008), and control of neuronal activity to examine network connectivity and behavior through optogenetic approaches (Huber et al., 2008; Petreanu et al., 2009). For such studies, knowledge of the genes expressed in the barrel cortex both under resting conditions and after neuronal stimulation is of crucial importance, in particular of those induced by sensory experience and their cortical layer and cellular expression patterns.

A limited number of studies have determined the expression of selected genes in barrel cortex after activation of the whisker system. Single-whisker experience induces cAMP responsive element (CRE)-dependent gene expression in the spared barrel of transgene reporter mice (Barth et al., 2000), whereas neuritin, a plasticity-related gene, shows differential regulation in spared and deprived barrels (Harwell et al., 2005). Passive whisker stimulation increases brain-derived neurotrophic factor $(B d n f)$ 

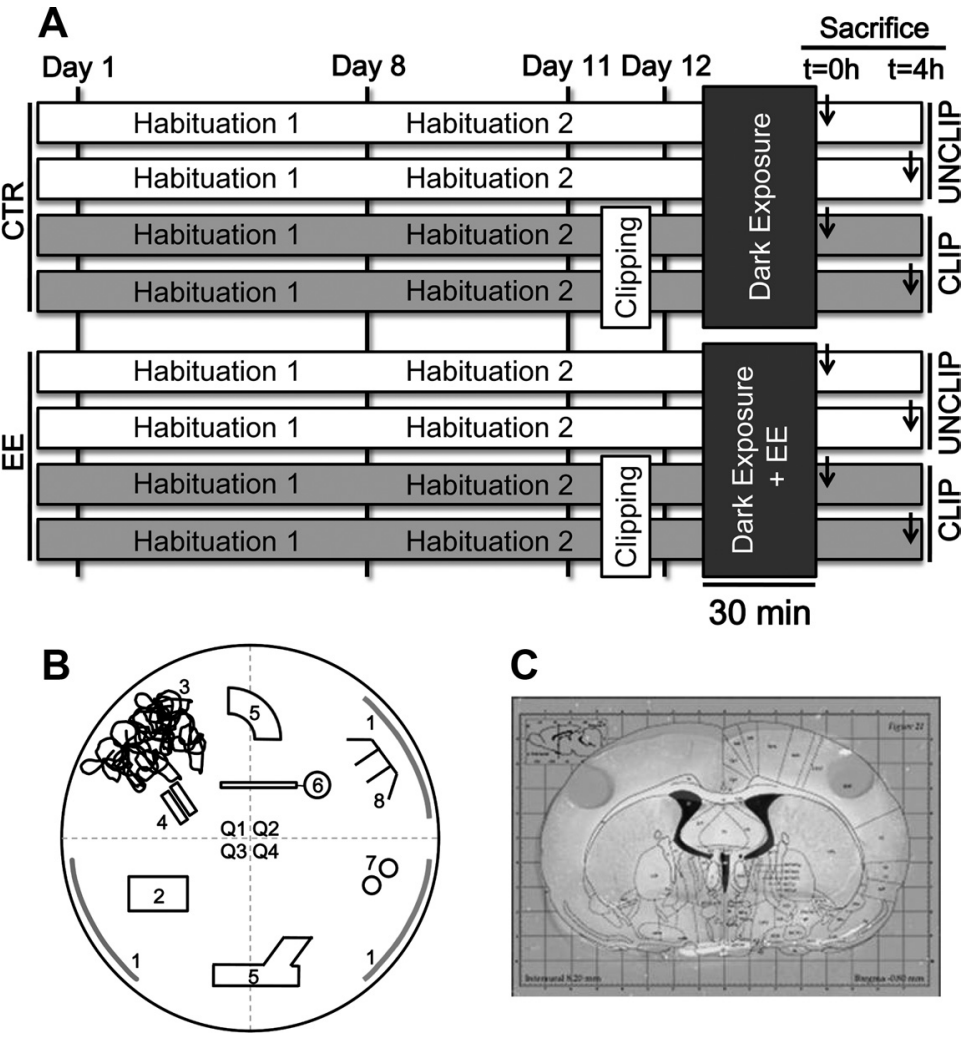

Figure 1. Overview of the experimental design and methods of tissue dissection. $\boldsymbol{A}$, General experimental design. The animals underwent a first habituation period for $7 \mathrm{~d}$, followed by a second habituation period of $5 \mathrm{~d}$. On day 11, the right whiskers of half of the rats were clipped (CLIP) under anesthesia; the other half received anesthesia only (UNCLIP). On day 12, the animals were exposed to the dark, with or without exposure to EE for $30 \mathrm{~min}$ (EE and CTR groups, respectively) and killed either immediately $(t=$ $0 \mathrm{~h})$ or $4 \mathrm{~h}(t=4 \mathrm{~h})$ after the end of the experiment. $\boldsymbol{B}$, Enriched environment cage. The cage in which the rats were placed for a period of $30 \mathrm{~min}$. Shown are the EE attributes (1-8) and the quadrants (01-04). The EE objects used were (1) different textures, (2) grated plastic box, (3) curled paper, (4) foam pipes, (5) plastic pipes, (6) wooden brush, (7) plastic balls, and (8) plastic wire strainer. Care was taken to place these objects always in the same place at the beginning of the EE session. $C$, Dissection area. The barrel cortex was dissected, separately for left and right hemispheres, using a $2 \mathrm{~mm}$ micropunch. Shown is the remaining tissue after micropunch, overlaid to its corresponding stereotactic picture (Paxinos and Watson, 1998) showing that the area was always located in $\mathrm{S1}$ and spanned layers $1-6$.

(Rocamora et al., 1996), synaptophysin (Ishibashi, 2002), and mRNA of glial glutamate transporters (Genoud et al., 2006). In addition, sensory experience, such as EE, induces expression of the immediate-early genes cAMP responsive element modulator (Crem), Fos, JunB, and early-growth response 1 (Egr1) (Filipkowski et al., 2001; Bisler et al., 2002). However, a genomewide study on genes activated during sensory experience has not been performed yet. In the present study, we used microarray analysis and validation by quantitative PCR (qPCR) and in situ hybridization in combination with whisker clipping experiments to explore global EE-induced mRNA expression patterns in the barrel cortex of adult rats. A number of differentially expressed genes were identified, providing novel insights into the molecular cascades responsive to experience-dependent plasticity in the rodent somatosensory system.

\section{Materials and Methods}

Animals. Male Long-Evans rats (Harlan) were used, ranging in age from 65 to $75 \mathrm{~d}$. A total of $n=36$ animals were used for microarray and qPCR analysis (group size, $n=6-8$ ) and $n=24$ for in situ hybridization experiments (group size, $n=4$ ). The animals were housed two per cage $(37.8 \times 21.7 \times 18.0 \mathrm{~cm})$ in a controlled environment under a $12 \mathrm{~h}$ light/dark cycle with lights on at 6:30 A.M. Food and water were provided ad libitum. Experimental procedures were performed between 7:30 A.M. and 2:30 P.M. All the experimental groups were constructed using matched weight criteria. The experiments were approved by the Animal Ethics Committee of the Radboud University Nijmegen (Nijmegen, The Netherlands), according to Dutch legislation.

Experimental procedure. A schematic overview of the experimental procedure is depicted in Figure $1 A$. To reduce stress levels, all rats underwent two habituation periods. During the first period, lasting $7 \mathrm{~d}$, the rats were handled and weighed daily. In the second period, lasting $5 \mathrm{~d}$, the rats were placed per two in the empty test cage (round, plastic cage; $0.88 \mathrm{~m}^{2}$ ) for $30 \mathrm{~min}$ on a daily basis. Note that two rats from the same home cage were placed together in the test cage and not individually or in a larger group, to avoid stress caused by isolation or by exposure to "stranger" rats (rats from other home cages). To prevent any visual stimulation and promote mainly the use of the somatosensory system, the test cage was located in a room without illumination. The procedures to which the rats were subjected during the five habituation sessions in the empty test cage during the second habitation period were identical to the procedures applied during the actual EE session. Because of this, stress during the EE session can be assumed to be very low. For clarity, the habituation sessions are not part of the sensory enrichment manipulation. After the habituation period, all the rats underwent a short (2-3 $\mathrm{min}) 2 \%$ isoflurane mixed gas $\mathrm{O}_{2}$ anesthesia (Pharmachemie BV). During anesthesia, the right whiskers of half of the animals were clipped as close to the skin as possible (CLIP), whereas the whiskers of the other rats were left intact (UNCLIP). The following day, both groups were transferred to a room without illumination, where they either stayed in their home cage (CTR) or were allowed to explore the enriched test cages, per two (EE), in a single session of $30 \mathrm{~min}$. Exploration of the EE took place in the dark to increase somatosensory (vs visual) stimulation. The objects used for enrichment are depicted in Figure $1 B$; the position of the objects was kept as similar as possible between the tests. To quantify behavior (see below, Behavioral analysis), all sessions were videotaped using infrared cameras (Velleman). The animals from the experimental (EE) group consistently displayed high levels of activity. In contrast, we observed that, most of the time, CTR animals were inactive in their home cage, and therefore the behavior of CTR animals was not quantified. For microarray and qPCR analysis, the rats were decapitated either immediately after the end of the EE session $(t=0 \mathrm{~h})$ or $4 \mathrm{~h}$ later $(t=4 \mathrm{~h})$. After decapitation, the brains were carefully dissected, frozen on dry ice, and stored at $-80^{\circ} \mathrm{C}$ until additional analysis. For in situ hybridization analysis, CTR animals were killed immediately $(t=0 \mathrm{~h})$, whereas EE animals were killed either immediately $(t=0 \mathrm{~h})$ or $4 \mathrm{~h}(t=4 \mathrm{~h})$ after enrichment. The animals were killed by terminal anesthesia with sodium pentobarbital $(90 \mathrm{mg} / \mathrm{kg}$, i.p.), followed by intracardiac perfusion with ice-cold $0.9 \%$ saline for 1-2 min and perfusion fixation with $4 \%$ ice-cold paraformaldehyde (PFA), $\mathrm{pH}$ 7.4, for $10 \mathrm{~min}$ (perfusion rate, $25-30 \mathrm{ml} / \mathrm{min}$ ). The brains were dissected, postfixed overnight in $4 \% \mathrm{PFA}$ at $4^{\circ} \mathrm{C}$, and transferred to $30 \%$ sucrose in $\mathrm{PBS}$ at $4^{\circ} \mathrm{C}$ until sectioning.

Behavioral analysis. The behaviors of all EE animals (both UNCLIP and CLIP groups) were quantified using The Observer 5.0 (Noldus Information Technology). A period of $10 \mathrm{~min}$ was analyzed, starting $10 \mathrm{~min}$ after the beginning of the EE exposure. The behavior was divided into six different categories, namely "fighting," "gnawing," "grooming," "rear- 
Table 1. Primers for quantitative PCR

\begin{tabular}{|c|c|c|c|}
\hline Gene & Forward primer $\left(5^{\prime}-3^{\prime}\right)$ & Reverse primer $\left(5^{\prime}-3^{\prime}\right)$ & Amplicon size (bp) \\
\hline Abcg2 & TTCTCATGACGATCTCTTTTGTGTT & CATATCGAGGAATGCTAAAGTACTGAA & 114 \\
\hline Apold1 & CGGGTCCAGCTCTGTACCA & GCTGCGAATCTAGAACATTCCA & 121 \\
\hline Arc & CCGTCCCCTCCTCTCTTGA & AAGGCACCTCCTCTTTGTAATCCTAT & 89 \\
\hline BDNF & GGTCACAGCGGCAGATAAAAAGAC & TTCGGCATTGCGAGTTCCAG & 188 \\
\hline Btg2 & TCCTGAGGACTCGGGGCTGC & GCGATAGCCGGAGCCCTTGG & 131 \\
\hline Fos & TCCCAGCTGCACTACCTATACGT & TGCGCAGCTAGGGAAGGA & 73 \\
\hline Ch25h & CCGTTTGGCTGGTACGGGGG & CAGGCGCTTCGAGTGGGGTG & 135 \\
\hline Chrm4 & AGAGTGCCCTGCTAATGTTGCT & CTAATTGACTCAGTGCCCTGGAA & 145 \\
\hline CycA & AGCACTGGGGAGAAAGGATT & AGCCACTCAGTCTTGGCAGT & 248 \\
\hline Cyr61 & AACTCGGAGTGCCGCCTGGT & GCCGCAGTATTTGGGCCGGT & 183 \\
\hline Dusp1 & AGGACAACCACAAGGCAGACA & CCAGCATCCTTGATGGAGTCTAT & 76 \\
\hline Egr3 & AAGCGCCACGCCAAGAT & GGCGCCGAGGATGCA & 80 \\
\hline FosB & ACGCACCCCCCAACCT & AGGAAGTGTACGAAGGGCTAACA & 96 \\
\hline Nptx2 & AGCGTCTCCTGGACTTGTAGCTA & TCGGGAATAGATGCCTTGAACT & 87 \\
\hline $\mathrm{Nr} 4 \mathrm{a} 2$ & САTTTCTGCCTTCTCCTGCATT & AAGTCACATGGTCTTTAAGACAAGACAATTTACA & 125 \\
\hline Pcsk1 & AATCTCACCTGGCGAGATATGC & ATCAAGCCCGCTCCATTCT & 101 \\
\hline Pde7b & CGCGCTGGGTTTCGAA & GCTTTTGTACACTTGGATCAACGA & 72 \\
\hline Plat & GCAGGGAAGTATACCACGGAGTT & TGGGTGCCACGGTAAGTCA & 100 \\
\hline Prom1 & СTTCTTTTGTATGTGCCGTTGCT & AACGCGATGCCAAGACTCA & 141 \\
\hline Ywhaz & TTGAGCAGAAGACGGAAGGT & GAAGCATTGGGGATCAAGAA & 136 \\
\hline $\boldsymbol{\beta}$-Actin & CGTGAAAAGATGACCCAGATCA & AGAGGCATACAGGGACAACACA & 89 \\
\hline
\end{tabular}

Shown are the names of the genes selected for qPCR analysis, the sequences of the forward and reverse primers from $5^{\prime}$ to $3^{\prime}$, and the size of the final product. The tested housekeeping genes are in bold.

Table 2. Primers for probe template generation (in situ hybridization)

\begin{tabular}{|c|c|c|c|}
\hline Genes & External primers $\left(5^{\prime}-3^{\prime}\right)$ & Internal primers $\left(5^{\prime}-3^{\prime}\right)$ & Amplicon size (bp) \\
\hline \multicolumn{4}{|l|}{ Apold1 } \\
\hline Forward & & ААTTAACCCTCACTAAAGGGTCTCTCTGATCTTCTGCAATTCCC & \multirow[t]{2}{*}{301} \\
\hline Reverse & & TAATACGACTCACTATAGGGTCCAGGCTCTCAGACAGTTTCTG & \\
\hline Forward & CTTTCCAGCCAGCCCCAGGC & AATTAACCCTCACTAAAGGGGAGTGCCGGCATCTTGGGGG & \multirow[t]{2}{*}{601} \\
\hline Reverse & CGGTGTGGGTGCGGATGTGA & TAATACGACTCACTATAGGGCTGGAAGGGCTTGTGGCCCG & \\
\hline \multicolumn{4}{|l|}{$\mathrm{Nr} 4 \mathrm{a} 2$} \\
\hline \multicolumn{4}{|c|}{ 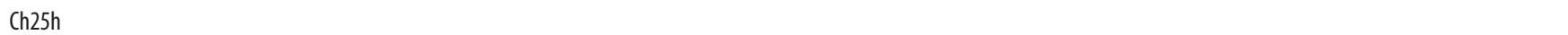 } \\
\hline Forward & AAGGACGGGAGAGGCGTCCG & AATTAACCCTCACTAAAGGGTCAGATGCACAACTACCAGCAAC & \multirow[t]{2}{*}{653} \\
\hline Reverse & ACAGGCGCTTCGAGTGGGGT & TAATACGACTCACTATAGGGCAGCAAAGCCAGGAATCTTCTCT & \\
\hline \multicolumn{4}{|l|}{ Btg2 } \\
\hline Forward & TCCTGAGGACTCGGGGCTGC & АATTAACCCTCACTAAAGGGGGTTTTCAGTAGGGCGCTCCAGG & \multirow[t]{2}{*}{305} \\
\hline Reverse & TGGACTGCTCCTGCCCAGCAT & TAATACGACTCACTATAGGGGGCTGGGAGGCCCAGTTCCA & \\
\hline Forward & & AATTAACCCTCACTAAAGGGTCACCGGCAGAAGACAGAGAAC & \multirow[t]{2}{*}{605} \\
\hline Reverse & & TAATACGACTCACTATAGGGAGCAGTTGGCGATGTTGATGAT & \\
\hline \multicolumn{4}{|c|}{ 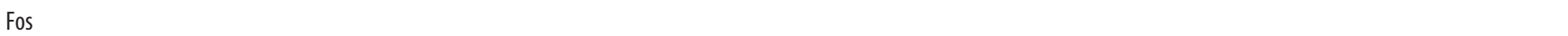 } \\
\hline Forward & AACTTTATCCCCACGGTGACAG & AATTAACCCTCACTAAAGGGAGAATCCGAAGGGAAAGGAATA & \multirow[t]{2}{*}{702} \\
\hline Reverse & TGAACATGGACGCTGAAGAGC & TAATACGACTCACTATAGGGAGCTCAGTGAGTCAGAGGAGGG & \\
\hline
\end{tabular}

Shown are the names of the genes selected for in situ hybridization, the sequences of the forward and reverse external and internal primers from $5^{\prime}$ to $3^{\prime}$, and the size of the final product after the second (internal) PCR reaction. The $T 3$ (5'AATTAACCCTCACTAAAGGG3') and T7 (5' TAATACGACTCACTATAGGG3') RNA polymerase sequences at the 5' of the internal forward and reverse primers are highlighted in bold. The Arc plasmid containing the full-length rat Arc CDNA subcloned into the EcoRI-Xhol site of pBluescriptll SK + (Stratagene) was provided by Dr P. F. Worley (John Hopkins University). The plasmid was linearized with EcoRI or Xhol and transcribed with T7 or SP6 RNA polymerases to generate antisense and sense probes, respectively.

ing," "whisking," and a final category with all other behaviors, called "other." The time spans of these different categories were measured. Next to this, the cage was divided into different quadrants (Fig. $1 B$ ), and the total time spent in these quadrants was also quantified. Levene's test was performed to test the homogeneity of the data. In case of nonhomogeneous data, a log transformation was executed. Subsequently, two-way ANOVAs (with "behavior" and "clipping" or "behavior" and "quadrant" as factors), followed by Student-Newman-Keuls (SNK) post hoc analyses when appropriate, were performed, with a significance level of $p \leq 0.05$. All tests were executed using SPSS 17.0 (SPSS Inc.).
Tissue processing. All procedures were performed under RNase-free conditions. For microarray and quantitative PCR analysis, the brains were sliced into $300 \mu \mathrm{m}$ coronal sections using a cryotome (Leica) at $-15^{\circ} \mathrm{C}$ and mounted on glass slides. Cytochrome oxidase-stained reference sections were used as a template to locate the barrel cortex, following stereotactic coordinates (Paxinos and Watson, 1998). Punches of barrel cortex (Fig. 1C) were taken bilaterally using a $2 \mathrm{~mm}$ micropunch (Harris Inc.), and samples from each hemisphere were collected separately and stored at $-80^{\circ} \mathrm{C}$ before RNA isolation took place. For in situ hybridization, the brains were sliced into $40 \mu \mathrm{m}$ coronal sections using a sliding microtome (Microm HM440E; Thermo Fisher Scientific). Sections were stored at $-20^{\circ} \mathrm{C}$ in cryoprotectant 
Table 3. List of differentially expressed genes identified by microarray after EE, ordered by $q$ value (smallest to largest)

\begin{tabular}{|c|c|c|c|c|c|c|c|}
\hline \multirow{2}{*}{$\begin{array}{l}\text { Affymetrix } \\
\text { transcripts cluster ID } \\
10767767\end{array}$} & \multirow{2}{*}{$\begin{array}{l}\text { Gene symbol } \\
\text { Btg2 }\end{array}$} & \multirow{2}{*}{$\begin{array}{l}\text { Gene title } \\
\text { BTG family, member } 2\end{array}$} & \multirow{2}{*}{$\begin{array}{l}\text { SAM } q \text { value } \\
8.78 \mathrm{E}-08\end{array}$} & \multicolumn{2}{|c|}{$\mathrm{FC} t=0 \mathrm{~h}$} & \multicolumn{2}{|c|}{$\mathrm{FC} t=4 \mathrm{~h}$} \\
\hline & & & & 5.01 & Up & 1.16 & Up \\
\hline 10899387 & Nr4a1 & Nuclear receptor subfamily 4, group A, member 1 & $8.78 \mathrm{E}-08$ & 3.14 & Up & 1.11 & Up \\
\hline 10732652 & Dusp1 & Dual specificity phosphatase 1 & $1.32 \mathrm{E}-07$ & 3.26 & Up & 1.06 & Up \\
\hline 10827231 & Cyr61 & Cysteine-rich, angiogenic inducer, 61 & $3.07 \mathrm{E}-07$ & 6.48 & Up & 1.10 & Up \\
\hline 10859262 & Apold1 & Apolipoprotein L domain containing 1 & $3.51 \mathrm{E}-07$ & 6.45 & Up & 1.10 & Up \\
\hline 10886031 & Fos & FBJ osteosarcoma oncogene & $7.91 \mathrm{E}-07$ & 3.78 & Up & 1.05 & Down \\
\hline 10720215 & Zfp36 & Zinc finger protein 36 & $8.78 \mathrm{E}-07$ & 3.10 & Up & 1.06 & Up \\
\hline 10832197 & Sik1 & Salt-inducible kinase 1 & $1.01 \mathrm{E}-06$ & 2.47 & Up & 1.02 & Down \\
\hline 10868940 & $\mathrm{Nr} 4 \mathrm{a} 3$ & Nuclear receptor subfamily 4, group A, member 3 & $1.10 \mathrm{E}-06$ & 2.68 & Up & 1.14 & Up \\
\hline 10845384 & Nr4a2 & Nuclear receptor subfamily 4, group A, member 2 & $1.14 \mathrm{E}-06$ & 3.20 & Up & 2.02 & Up \\
\hline 10806585 & JunB & JunB proto-oncogene & $1.23 \mathrm{E}-06$ & 2.86 & Up & 1.14 & Down \\
\hline 10734882 & Per1 & Period homolog 1 (Drosophila) & $1.80 \mathrm{E}-06$ & 1.65 & Up & 1.02 & Down \\
\hline 10770710 & Atf3 & Activating transcription factor 3 & $2.02 \mathrm{E}-06$ & 2.05 & Up & 1.23 & Up \\
\hline 10900358 & Gadd45b & Growth arrest and DNA-damage-inducible, $\beta$ & $2.28 \mathrm{E}-06$ & 1.90 & Up & 1.10 & Up \\
\hline 10735866 & rno-mir-212 & miR-212 stem-loop & $2.77 \mathrm{E}-06$ & 1.89 & Up & 1.12 & Up \\
\hline 10719432 & FosB & FBJ osteosarcoma oncogene B & $2.90 \mathrm{E}-06$ & 2.08 & Up & 1.07 & Up \\
\hline 10796543 & Arl5b & ADP-ribosylation factor-like 5B & $2.94 \mathrm{E}-06$ & 1.75 & Up & 1.10 & Up \\
\hline 10792421 & Plat & Plasminogen activator, tissue & $3.03 \mathrm{E}-06$ & 1.74 & Up & 1.10 & Down \\
\hline 10743966 & Kdm6b & Lysine (K)-specific demethylase 6B & $3.03 \mathrm{E}-06$ & 1.40 & Up & 1.08 & Up \\
\hline 10896793 & Trib1 & Tribbles homolog 1 (Drosophila) & $3.12 \mathrm{E}-06$ & 1.93 & Up & 1.14 & Up \\
\hline 10909356 & Snord14 & Small nucleolar RNA SNORD14 & $3.38 \mathrm{E}-06$ & 2.75 & Up & 1.13 & Down \\
\hline 10790670 & $\mathrm{KIf} 2$ & Kruppel-like factor 2 (lung) & $3.69 \mathrm{E}-06$ & 1.42 & Up & 1.04 & Down \\
\hline 10737506 & Tob1 & Transducer of ErbB-2.1 & $3.78 \mathrm{E}-06$ & 1.53 & Up & 1.11 & Down \\
\hline 10823508 & Cenl1 & Cyclin L1 & $5.97 \mathrm{E}-06$ & 1.58 & Up & 1.09 & Down \\
\hline 10923866 & Zdbf2 & Zinc finger, DBF-type containing 2 & $6.28 \mathrm{E}-06$ & 1.59 & Up & 1.33 & Up \\
\hline 10744376 & Bcl6b & B-cell CLL/lymphoma 6, member B (zinc finger protein) & $6.50 \mathrm{E}-06$ & 1.51 & Up & 1.11 & Up \\
\hline 10781337 & Egr3 & Early growth response 3 & $6.50 \mathrm{E}-06$ & 1.51 & Up & 1.80 & Up \\
\hline 10878938 & Plk3 & Polo-like kinase 3 (Drosophila) & $6.90 \mathrm{E}-06$ & 1.64 & Up & 1.02 & Up \\
\hline 10873578 & Snora15 & Small nucleolar RNA SNORA15 & $7.42 \mathrm{E}-06$ & 1.74 & Up & 1.11 & Down \\
\hline 10721865 & Ppp1r15a & Protein phosphatase 1, regulatory (inhibitor) subunit $15 \mathrm{~A}$ & $8.35 \mathrm{E}-06$ & 1.74 & Up & 1.06 & Down \\
\hline 10903998 & U6 & U6 spliceosomal RNA & $8.39 \mathrm{E}-06$ & 1.98 & Up & 1.08 & Down \\
\hline 10795616 & Crem & cAMP responsive element modulator & $9.40 \mathrm{E}-06$ & 1.51 & Up & 1.29 & Up \\
\hline 10774375 & Peli1 & Pellino 1 & $9.53 \mathrm{E}-06$ & 1.34 & Up & 1.10 & Down \\
\hline 10861986 & Insig1 & Insulin induced gene 1 & $9.53 \mathrm{E}-06$ & 1.23 & Up & 1.10 & Down \\
\hline 10731193 & rno-mir-212 & rno-mir-212 stem-loop & $9.66 \mathrm{E}-06$ & 1.61 & Up & 1.03 & Down \\
\hline 10834447 & Egfl7 & EGF-like-domain, multiple 7 & $1.04 \mathrm{E}-05$ & 1.41 & Up & 1.00 & Up \\
\hline 10788483 & Lonrf1 & LON peptidase $\mathrm{N}$-terminal domain and ring finger 1 & $1.18 \mathrm{E}-05$ & 1.33 & Up & 1.15 & Down \\
\hline 10820666 & Hmgcr & 3-Hydroxy-3-methylglutaryl-coenzyme A reductase & $1.26 \mathrm{E}-05$ & 1.32 & Up & 1.01 & Up \\
\hline 10822330 & Zbtb10 & Zinc finger and BTB domain containing 10 & $1.28 \mathrm{E}-05$ & 1.48 & Up & 1.11 & Down \\
\hline 10773115 & Prom1 & Prominin 1 & $1.31 \mathrm{E}-05$ & 1.00 & Up & 1.64 & Down \\
\hline 10876838 & Klf4 & Kruppel-like factor 4 (gut) & $1.33 \mathrm{E}-05$ & 1.53 & Up & 1.06 & Up \\
\hline 10824409 & U6 & U6 spliceosomal RNA & $1.48 \mathrm{E}-05$ & 1.59 & Up & 1.19 & Down \\
\hline 10760290 & Nptx2 & Neuronal pentraxin 2 & $1.49 \mathrm{E}-05$ & 1.18 & Up & 1.45 & Up \\
\hline 10764551 & Ptgs 2 & Prostaglandin-endoperoxide synthase 2 & $1.59 \mathrm{E}-05$ & 1.61 & Up & 1.01 & Down \\
\hline 10873814 & Klf4 & Kruppel-like factor 4 (gut) & $1.60 \mathrm{E}-05$ & 1.77 & Up & 1.06 & Up \\
\hline 10752839 & Adamts1 & ADAM metallopeptidase with thrombospondin type 1 motif, 1 & $1.66 \mathrm{E}-05$ & 1.43 & Up & 1.12 & Up \\
\hline 10817552 & Txnip & Thioredoxin interacting protein & $1.87 \mathrm{E}-05$ & 1.29 & Up & 1.29 & Down \\
\hline 10702025 & Ahi1 & Abelson helper integration site 1 & $1.87 \mathrm{E}-05$ & 1.28 & Up & 1.07 & Down \\
\hline
\end{tabular}


Table 3. Continued

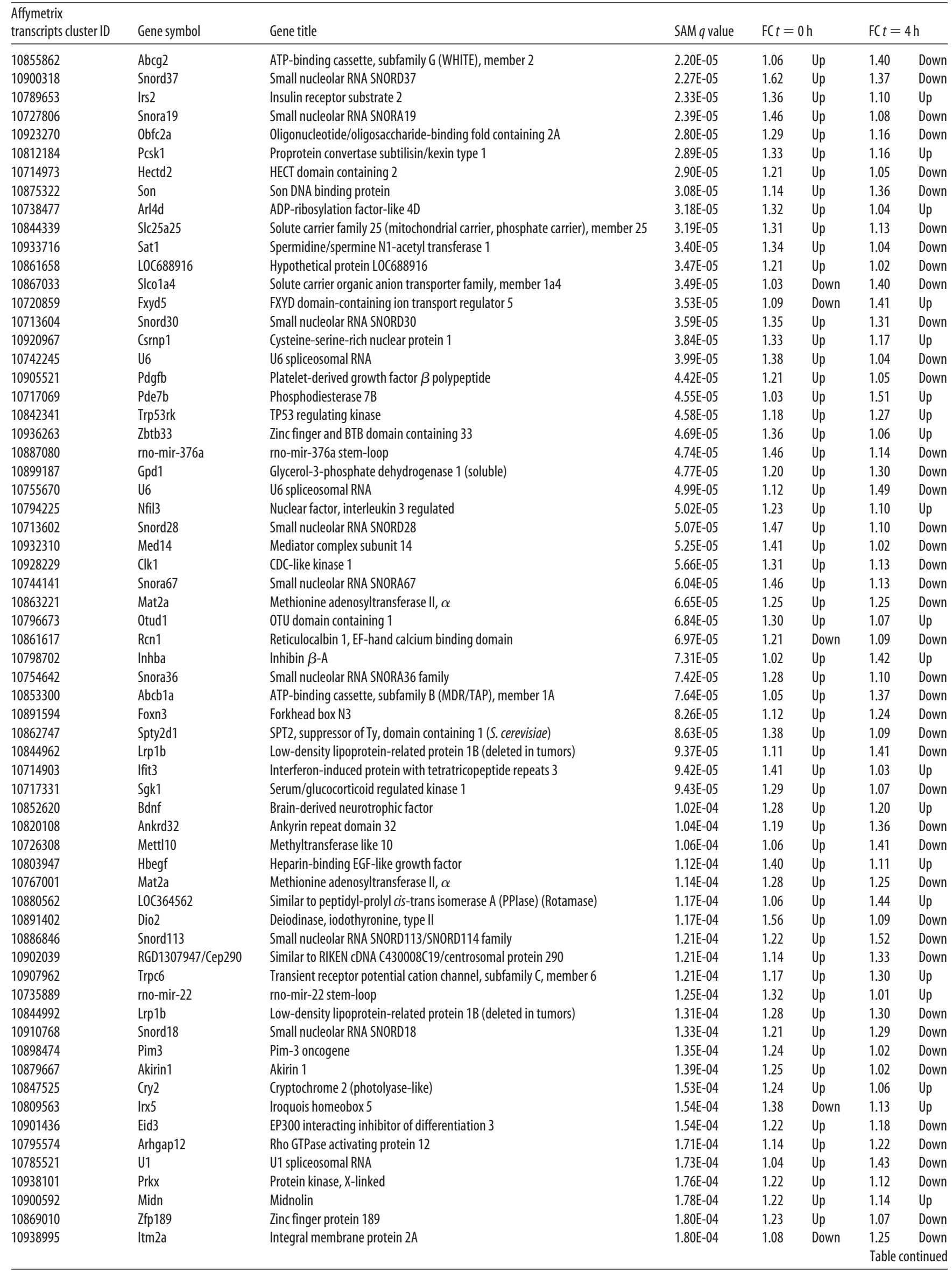


Table 3. Continued

\begin{tabular}{|c|c|c|c|c|c|c|c|}
\hline \multirow{2}{*}{$\begin{array}{l}\text { Affymetrix } \\
\text { transcripts cluster ID } \\
10716136\end{array}$} & \multirow{2}{*}{$\begin{array}{l}\text { Gene symbol } \\
\text { Pdcd4 }\end{array}$} & \multirow{2}{*}{$\begin{array}{l}\text { Gene title } \\
\text { Programmed cell death } 4\end{array}$} & \multirow{2}{*}{$\begin{array}{l}\text { SAM } q \text { value } \\
1.81 \mathrm{E}-04\end{array}$} & \multicolumn{2}{|c|}{$\mathrm{FC} t=0 \mathrm{~h}$} & \multicolumn{2}{|c|}{$\mathrm{FC} t=4 \mathrm{~h}$} \\
\hline & & & & 1.23 & Up & 1.37 & Down \\
\hline 10868428 & Dnajb5 & DnaJ (Hsp40) homolog, subfamily B, member 5 & $1.84 \mathrm{E}-04$ & 1.24 & Up & 1.17 & Up \\
\hline 10762028 & Snora67 & Small nucleolar RNA SNORA67 & $1.89 \mathrm{E}-04$ & 1.31 & Up & 1.02 & Down \\
\hline 10878219 & Usp15 & Ubiquitin-specific peptidase 15 & $1.90 \mathrm{E}-04$ & 1.20 & Up & 1.28 & Down \\
\hline 10803158 & Rock1 & Rho-associated coiled-coil containing protein kinase 1 & $2.00 \mathrm{E}-04$ & 1.14 & Up & 1.29 & Down \\
\hline 10770334 & Mixl1 & Mix1 homeobox-like 1 (Xenopus laevis) & 2.17E-04 & 1.25 & Down & 1.13 & Up \\
\hline 10778763 & Rel & v-rel reticuloendotheliosis viral oncogene homolog (avian) & $2.45 \mathrm{E}-04$ & 1.21 & Up & 1.04 & Down \\
\hline 10906950 & LOC100361136 & Hypothetical LOC100361136 & $2.53 \mathrm{E}-04$ & 1.35 & Up & 1.08 & Down \\
\hline 10884489 & G2e3 & G2/M-phase specific E3 ubiquitin ligase & 2.61E-04 & 1.36 & Up & 1.20 & Down \\
\hline 10866926 & LOC690728 & Similar to Protein C12orf11 (sarcoma antigen NY-SAR-95) & $2.72 \mathrm{E}-04$ & 1.21 & Up & 1.18 & Down \\
\hline 10938893 & rno-mir-325 & rno-mir-325 stem-loop & 2.79E-04 & 1.16 & Up & 1.45 & Down \\
\hline 10763421 & Dsel & Dermatan sulfate epimerase-like & $3.29 \mathrm{E}-04$ & 1.02 & Down & 1.46 & Down \\
\hline 10840007 & Hspa12b & Heat shock protein 12B & $3.34 \mathrm{E}-04$ & 1.35 & Down & 1.01 & Up \\
\hline 10725112 & Snord14 & Small nucleolar RNA SNORD14 & $3.38 \mathrm{E}-04$ & 1.32 & Up & 1.14 & Down \\
\hline 10779681 & U1 & U1 spliceosomal RNA & $3.41 \mathrm{E}-04$ & 1.44 & Up & 1.36 & Down \\
\hline 10779683 & Ktn1 & Kinectin 1 & $3.41 \mathrm{E}-04$ & 1.12 & Up & 1.23 & Down \\
\hline 10866410 & Gpr19 & G-protein-coupled receptor 19 & $3.48 \mathrm{E}-04$ & 1.23 & Up & 1.04 & Down \\
\hline 10863676 & Egr4 & Early growth response 4 & $3.56 \mathrm{E}-04$ & 1.24 & Up & 1.27 & Up \\
\hline 10934154 & Stard8 & StAR-related lipid transfer (START) domain containing 8 & $3.59 \mathrm{E}-04$ & 1.07 & Down & 1.21 & Up \\
\hline 10929729 & GbX2 & Gastrulation brain homeobox 2 & $3.72 \mathrm{E}-04$ & 1.28 & Down & 1.13 & Up \\
\hline 10755127 & Snora63 & Small nucleolar RNA SNORA63 & $3.78 \mathrm{E}-04$ & 1.39 & Up & 1.43 & Down \\
\hline 10774681 & Smek2 & SMEK homolog 2, suppressor of mek1 (Dictyostelium) & $3.93 \mathrm{E}-04$ & 1.21 & Up & 1.18 & Down \\
\hline 10929319 & Rab18 & RAB18, member RAS oncogene family & $3.93 \mathrm{E}-04$ & 1.14 & Up & 1.36 & Down \\
\hline 10778399 & Mospd1 & Motile sperm domain containing 1 & $4.56 \mathrm{E}-04$ & 1.32 & Up & 1.14 & Down \\
\hline 10746040 & U6 & U6 spliceosomal RNA & 4.64E- 04 & 1.29 & Up & 1.23 & Down \\
\hline 10935021 & Armex 5 & Armadillo repeat containing, X-linked 5 Gene & $4.70 \mathrm{E}-04$ & 1.26 & Up & 1.02 & Down \\
\hline 10719616 & PVR & Poliovirus receptor & 4.81E-04 & 1.23 & Up & 1.07 & Down \\
\hline 10714254 & LOC499330 & Similar to nicotinamide riboside kinase 1 & 4.87E-04 & 1.09 & Up & 1.44 & Down \\
\hline 10869137 & Fktn & Fukutin & $4.88 \mathrm{E}-04$ & 1.15 & Up & 1.27 & Down \\
\hline 10797857 & Edn1 & Endothelin 1 & $4.96 \mathrm{E}-04$ & 1.31 & Up & 1.08 & Down \\
\hline 10918535 & Fam63b & Family with sequence similarity 63 , member $B$ & $5.21 \mathrm{E}-04$ & 1.15 & Up & 1.28 & Down \\
\hline 10722315 & U6 & U6 spliceosomal RNA & $5.22 \mathrm{E}-04$ & 1.50 & Down & 1.11 & Down \\
\hline 10795344 & Q63290_RAT & L1 retroposon, ORF2 mRNA, fragment & $5.25 \mathrm{E}-04$ & 1.31 & Down & 1.23 & Up \\
\hline 10760112 & Rnf6 & Ring finger protein (C3H2C3 type) 6 & $5.29 \mathrm{E}-04$ & 1.10 & Up & 1.30 & Down \\
\hline 10911309 & Gtf2a2 & General transcription factor IIA, 2 & $5.45 \mathrm{E}-04$ & 1.35 & Up & 1.11 & Up \\
\hline 10809766 & LOC364956 & Hypothetical LOC364956 & $5.50 \mathrm{E}-04$ & 1.41 & Down & 1.04 & Up \\
\hline 10899378 & Grasp & GRP1 (general receptor for phosphoinositides 1)-associated scaffold protein & $5.61 \mathrm{E}-04$ & 1.23 & Up & 1.25 & Up \\
\hline 10828154 & Hspa1 & Heat shock protein 1 & $5.63 \mathrm{E}-04$ & 1.69 & Up & 1.04 & Up \\
\hline 10844968 & Lrp1b & Low-density lipoprotein-related protein 1B (deleted in tumors) & $5.70 \mathrm{E}-04$ & 1.19 & Up & 1.21 & Down \\
\hline 10927717 & Kdelc1 & KDEL (Lys-Asp-Glu-Leu) containing 1 & $5.70 \mathrm{E}-04$ & 1.09 & Up & 1.20 & Down \\
\hline 10748999 & Slc25a19 & Solute carrier family 25 (mitochondrial thiamine pyrophosphate carrier), member 19 & $5.89 \mathrm{E}-04$ & 1.06 & Down & 1.20 & Down \\
\hline 10869644 & U6 & U6 spliceosomal RNA & $6.00 \mathrm{E}-04$ & 1.42 & Down & 1.14 & Down \\
\hline 10806913 & Usp38 & Ubiquitin specific peptidase 38 & 6.09E-04 & 1.31 & Up & 1.10 & Down \\
\hline 10885600 & Cwc22 & CWC22 spliceosome-associated protein homolog (S. cerevisiae) & $6.14 \mathrm{E}-04$ & 1.19 & Up & 1.27 & Down \\
\hline 10914788 & Birc2 & Baculoviral IAP repeat-containing 2 & $6.16 \mathrm{E}-04$ & 1.25 & Up & 1.20 & Down \\
\hline 10914682 & Dync2h1 & Dynein cytoplasmic 2 heavy chain 1 & $6.16 \mathrm{E}-04$ & 1.11 & Up & 1.30 & Down \\
\hline 10822637 & Skil & SKI-like oncogene & $6.29 \mathrm{E}-04$ & 1.24 & Up & 1.02 & Up \\
\hline 10903657 & LOC314942 & Similar to CUB and Sushi multiple domains 3 isoform 1 & $6.38 \mathrm{E}-04$ & 1.06 & Up & 1.33 & Down \\
\hline
\end{tabular}


Table 3. Continued

\begin{tabular}{|c|c|c|c|c|c|c|c|}
\hline \multirow{2}{*}{$\begin{array}{l}\text { Affymetrix } \\
\text { transcripts cluster ID } \\
10775157\end{array}$} & \multirow{2}{*}{$\begin{array}{l}\text { Gene symbol } \\
\text { LOC689986 }\end{array}$} & \multirow{2}{*}{$\begin{array}{l}\text { Gene title } \\
\text { Hypothetical protein LOC689986 }\end{array}$} & \multirow{2}{*}{$\begin{array}{l}\text { SAM } q \text { value } \\
6.46 \mathrm{E}-04\end{array}$} & \multicolumn{2}{|c|}{$\mathrm{FC} t=0 \mathrm{~h}$} & \multicolumn{2}{|c|}{$\mathrm{FC} t=4 \mathrm{~h}$} \\
\hline & & & & 1.44 & Up & 1.03 & Up \\
\hline 10799835 & Nsun6 & NOL1/NOP2/Sun domain family, member 6 & $6.54 \mathrm{E}-04$ & 1.25 & Up & 1.08 & Down \\
\hline 10829163 & Snora36 & Small nucleolar RNA SNORA36 family & $6.68 \mathrm{E}-04$ & 1.25 & Up & 1.09 & Down \\
\hline 10826547 & Mett|14 & Methyltransferase like 14 & $6.95 \mathrm{E}-04$ & 1.16 & Up & 1.30 & Down \\
\hline 10912525 & Stag1 & Stromal antigen 1 & $7.25 \mathrm{E}-04$ & 1.15 & Up & 1.21 & Down \\
\hline 10788655 & Mak16 & MAK16 homolog (S. cerevisiae) & $7.78 \mathrm{E}-04$ & 1.04 & Up & 1.27 & Down \\
\hline 10912229 & Plscr2 & Phospholipid scramblase 2 & $7.86 \mathrm{E}-04$ & 1.27 & Up & 1.26 & Down \\
\hline 10772072 & Uba6 & Ubiquitin-like modifier activating enzyme 6 & 7.87E-04 & 1.22 & Up & 1.02 & Up \\
\hline 10786995 & LOC290577 & Hypothetical LOC290577 & $7.91 \mathrm{E}-04$ & 1.23 & Up & 1.17 & Down \\
\hline 10889522 & Dld & Dihydrolipoamide dehydrogenase & $8.04 \mathrm{E}-04$ & 1.25 & Up & 1.22 & Down \\
\hline 10845070 & Snord56 & Small nucleolar RNA SNORD56 & $8.13 \mathrm{E}-04$ & 1.34 & Up & 1.21 & Down \\
\hline 10815778 & Lekr1 & Leucine, glutamate and lysine rich 1 & $8.42 \mathrm{E}-04$ & 1.10 & Up & 1.26 & Down \\
\hline 10798737 & Arid4b & AT rich interactive domain $4 \mathrm{~B}$ (Rbp1 like) & $8.49 \mathrm{E}-04$ & 1.06 & Up & 1.25 & Down \\
\hline 10935589 & Htatsf1 & HIV-1 Tat specific factor 1 & $8.51 \mathrm{E}-04$ & 1.07 & Up & 1.31 & Down \\
\hline 10884853 & Prpf39 & PRP39 pre-mRNA processing factor 39 homolog (S. cerevisiae) & $8.57 \mathrm{E}-04$ & 1.18 & Up & 1.20 & Down \\
\hline 10766880 & Mir29b-2 & microRNA mir-29b-2 & $8.58 \mathrm{E}-04$ & 1.29 & Up & 1.14 & Down \\
\hline 10893368 & LOC692116 & Similar to RRS1 ribosome biogenesis regulator & 8.67E-04 & 1.09 & Down & 1.21 & Up \\
\hline 10890917 & Cwc22 & CWC22 spliceosome-associated protein homolog (S. cerevisiae) & $8.67 \mathrm{E}-04$ & 1.19 & Up & 1.25 & Down \\
\hline 10798902 & Mkx & Mohawk homeobox & $8.84 \mathrm{E}-04$ & 1.16 & Up & 1.23 & Down \\
\hline 10741664 & Rpl36a-ps2 & Similar to large subunit ribosomal protein L36a & $8.84 \mathrm{E}-04$ & 1.01 & Up & 1.39 & Up \\
\hline 10778620 & Slc1a4 & Solute carrier family 1 (glutamate/neutral amino acid transporter), member 4 & $8.86 \mathrm{E}-04$ & 1.29 & Up & 1.22 & Up \\
\hline 10701709 & Lats1 & LATS, large tumor suppressor, homolog 1 (Drosophila) & 8.95E-04 & 1.07 & Up & 1.33 & Down \\
\hline 10751769 & Atp13a3 & ATPase type $13 \mathrm{~A} 3$ & $8.97 \mathrm{E}-04$ & 1.14 & Up & 1.24 & Down \\
\hline 10933408 & Mospd2 & Motile sperm domain containing 2 & $9.67 \mathrm{E}-04$ & 1.23 & Up & 1.20 & Down \\
\hline 10850081 & RGD1564425 & Similar to proteasome subunit $\beta$ type 3 (proteasome $\theta$ chain) & $9.73 \mathrm{E}-04$ & 1.28 & Down & 1.16 & Up \\
\hline 10712057 & $0 \mid r 292$ & Olfactory receptor 292 & $1.00 \mathrm{E}-03$ & 1.10 & Down & 1.26 & Down \\
\hline 10747202 & Krt33b & Keratin 33B & $1.01 \mathrm{E}-03$ & 1.24 & Down & 1.05 & Up \\
\hline 10787017 & LOC290577 & Hypothetical LOC290577 & $1.01 \mathrm{E}-03$ & 1.30 & Up & 1.19 & Down \\
\hline 10772468 & Nfxl1 & Nuclear transcription factor, X-box binding-like 1 & $1.01 \mathrm{E}-03$ & 1.18 & Up & 1.29 & Down \\
\hline 10813347 & Ttc33 & Tetratricopeptide repeat domain 33 & $1.01 \mathrm{E}-03$ & 1.08 & Up & 1.24 & Down \\
\hline 10881063 & Clcnka & Chloride channel Ka & $1.03 \mathrm{E}-03$ & 1.21 & Down & 1.01 & Down \\
\hline 10719956 & Sdccag1 & Serologically defined colon cancer antigen 1 & $1.04 \mathrm{E}-03$ & 1.11 & Up & 1.25 & Down \\
\hline 10891659 & Rps6ka5 & Ribosomal protein 56 kinase, polypeptide 5 & $1.04 \mathrm{E}-03$ & 1.12 & Up & 1.28 & Down \\
\hline 10886784 & rno-mir-345 & rno-mir-345 stem-loop & $1.04 \mathrm{E}-03$ & 1.24 & Down & 1.02 & Down \\
\hline 10765671 & Dcaf8 & DDB1 and CUL4 associated factor 8 & $1.05 \mathrm{E}-03$ & 1.09 & Up & 1.27 & Down \\
\hline 10737426 & Tmem100 & Transmembrane protein 100 & $1.05 \mathrm{E}-03$ & 1.41 & Up & 1.13 & Up \\
\hline 10826403 & Snx7 & Sorting nexin 7 & $1.08 \mathrm{E}-03$ & 1.01 & Up & 1.20 & Up \\
\hline 10783868 & Gmpr2/Tinf2 & Guanosine monophosphate reductase 2/TERF1 (TRF1)-interacting nuclear factor 2 & $1.09 \mathrm{E}-03$ & 1.34 & Up & 1.00 & Up \\
\hline 10917290 & Hspb2 & Heat shock protein $\beta 2$ & $1.12 \mathrm{E}-03$ & 1.25 & Down & 1.07 & Up \\
\hline 10756270 & 5S_rRNA & $5 S$ ribosomal RNA & $1.13 \mathrm{E}-03$ & 1.32 & Down & 1.03 & Down \\
\hline 10901367 & RGD1309995 & Similar to CG13957-PA & $1.13 \mathrm{E}-03$ & 1.11 & Up & 1.25 & Down \\
\hline 10792035 & Dusp4 & Dual specificity phosphatase 4 & $1.14 \mathrm{E}-03$ & 1.35 & Up & 1.07 & Up \\
\hline 10804647 & $C d x 1$ & Caudal type homeobox 1 & $1.15 \mathrm{E}-03$ & 1.21 & Down & 1.02 & Up \\
\hline 10924076 & Rpe & Ribulose-5-phosphate-3-epimerase & $1.15 \mathrm{E}-03$ & 1.00 & Up & 1.23 & Down \\
\hline 10864968 & RGD1561270 & Similar to zinc finger protein 248 & $1.15 \mathrm{E}-03$ & 1.25 & Up & 1.17 & Down \\
\hline 10759435 & 5S_rRNA & 5 S ribosomal RNA & $1.15 \mathrm{E}-03$ & 1.32 & Down & 1.03 & Down \\
\hline 10836633 & Phospho2 & Phosphatase, orphan 2 & $1.15 \mathrm{E}-03$ & 1.31 & Up & 1.06 & Down \\
\hline 10833215 & Ddx50 & DEAD (Asp-Glu-Ala-Asp) box polypeptide 50 & $1.16 \mathrm{E}-03$ & 1.25 & Up & 1.07 & Down \\
\hline
\end{tabular}


Table 3. Continued

\begin{tabular}{|c|c|c|c|c|c|c|c|}
\hline \multirow{2}{*}{$\begin{array}{l}\text { Affymetrix } \\
\text { transcripts cluster ID } \\
10906428\end{array}$} & \multirow{2}{*}{$\begin{array}{l}\text { Gene symbol } \\
\text { Abcd2 }\end{array}$} & \multirow{2}{*}{$\begin{array}{l}\text { Gene title } \\
\text { ATP-binding cassette, subfamily D (ALD), member } 2\end{array}$} & \multirow{2}{*}{$\frac{\text { SAM } q \text { value }}{1.17 \mathrm{E}-03}$} & \multicolumn{2}{|c|}{$\mathrm{FC} t=0 \mathrm{~h}$} & \multicolumn{2}{|c|}{$\mathrm{FC} t=4 \mathrm{~h}$} \\
\hline & & & & 1.08 & Up & 1.23 & Down \\
\hline 10939319 & Armcx6 & Armadillo repeat containing, $X$-linked 6 & $1.18 \mathrm{E}-03$ & 1.04 & Up & 1.25 & Down \\
\hline 10759445 & 5S_rRNA & 5 S ribosomal RNA & $1.19 \mathrm{E}-03$ & 1.31 & Down & 1.04 & Down \\
\hline 10756268 & 5S_rRNA & 5S ribosomal RNA & $1.20 \mathrm{E}-03$ & 1.31 & Down & 1.04 & Down \\
\hline 10756272 & 5S_rRNA & 5 S ribosomal RNA & $1.20 \mathrm{E}-03$ & 1.32 & Down & 1.04 & Down \\
\hline 10763137 & 5S_rRNA & $5 S$ ribosomal RNA & $1.21 \mathrm{E}-03$ & 1.16 & Up & 1.25 & Down \\
\hline 10737380 & Rnft1 & Ring finger protein, transmembrane 1 & $1.21 \mathrm{E}-03$ & 1.42 & Up & 1.02 & Down \\
\hline 10795289 & Hist1h2ail & Histone cluster 1, H2ai-like & $1.22 \mathrm{E}-03$ & 1.34 & Down & 1.00 & Down \\
\hline 10826672 & Alpk1 & $\beta$-Kinase 1 & $1.23 \mathrm{E}-03$ & 1.03 & Up & 1.25 & Down \\
\hline 10844988 & Lrp1b & Low-density lipoprotein-related protein 1B (deleted in tumors) & $1.24 \mathrm{E}-03$ & 1.31 & Up & 1.38 & Down \\
\hline 10882511 & Morn2 & MORN repeat containing 2 & $1.25 \mathrm{E}-03$ & 1.11 & Down & 1.27 & Down \\
\hline 10875420 & LOC502940 & Pro-histogranin & $1.26 \mathrm{E}-03$ & 1.21 & Down & 1.13 & Up \\
\hline 10887336 & Snora28 & Small nucleolar RNA SNORA28 & $1.27 \mathrm{E}-03$ & 1.24 & Up & 1.32 & Down \\
\hline 10785865 & Abcc4 & ATP-binding cassette, subfamily C (CFTR/MRP), member 4 & $1.28 \mathrm{E}-03$ & 1.23 & Down & 1.11 & Up \\
\hline 10854303 & Cpa4 & Carboxypeptidase A4 & $1.28 \mathrm{E}-03$ & 1.19 & Down & 1.21 & Down \\
\hline 10936346 & Lonrf3 & LON peptidase $\mathrm{N}$-terminal domain and ring finger 3 & $1.31 \mathrm{E}-03$ & 1.09 & Up & 1.27 & Down \\
\hline 10825580 & Hipk1 & Homeodomain interacting protein kinase 1 & $1.34 \mathrm{E}-03$ & 1.15 & Up & 1.30 & Down \\
\hline 10752654 & Znf654 & Zinc finger protein 654 & $1.36 \mathrm{E}-03$ & 1.25 & Up & 1.06 & Down \\
\hline 10877896 & Fam29a & Family with sequence similarity 29, member A & $1.40 \mathrm{E}-03$ & 1.13 & Up & 1.49 & Down \\
\hline 10887966 & Hnrpll & Heterogeneous nuclear ribonucleoprotein L-like & $1.42 \mathrm{E}-03$ & 1.22 & Up & 1.02 & Up \\
\hline 10764404 & Zbtb41 & Zinc finger and BTB domain containing 41 & $1.42 \mathrm{E}-03$ & 1.26 & Up & 1.11 & Down \\
\hline 10703327 & RGD156237 & Similar to chromosome 6 open reading frame 70/LOC361485 & $1.42 \mathrm{E}-03$ & 1.13 & Up & 1.25 & Down \\
\hline 10843125 & Pcmtd2 & Protein-L-isoaspartate (D-aspartate) 0-methyltransferase domain containing 2 & $1.43 \mathrm{E}-03$ & 1.10 & Up & 1.24 & Down \\
\hline 10868669 & Zcchc7 & Zinc finger, $\mathrm{CCHC}$ domain containing 7 & $1.44 \mathrm{E}-03$ & 1.04 & Up & 1.25 & Down \\
\hline 10902614 & Rap1b & RAP1B, member of RAS oncogene family & $1.45 \mathrm{E}-03$ & 1.22 & Up & 1.06 & Down \\
\hline 10720126 & LOC687333 & Similar to zinc finger protein 59 & $1.45 \mathrm{E}-03$ & 1.26 & Up & 1.07 & Up \\
\hline 10868007 & Casp8ap2 & Caspase 8 associated protein 2 & $1.46 \mathrm{E}-03$ & 1.15 & Up & 1.25 & Down \\
\hline 10764626 & Ivns1abp & Influenza virus NS1A binding protein & $1.47 \mathrm{E}-03$ & 1.22 & Up & 1.01 & Down \\
\hline 10901039 & LOC100364912 & rCG29233-like & $1.50 \mathrm{E}-03$ & 1.21 & Up & 1.05 & Down \\
\hline 10815442 & Spg20 & Spastic paraplegia 20 (Troyer syndrome) homolog (human) & $1.50 \mathrm{E}-03$ & 1.11 & Up & 1.25 & Down \\
\hline 10850492 & RGD1308023 & Similar to CG5521-PA & $1.51 \mathrm{E}-03$ & 1.15 & Up & 1.24 & Down \\
\hline 10850958 & Pxmp4 & Peroxisomal membrane protein 4 & $1.56 \mathrm{E}-03$ & 1.21 & Down & 1.06 & Down \\
\hline
\end{tabular}

Shown are the Affymetrix transcripts cluster ID, gene symbol, gene title, SAM $q$ value, and fold change at $t=0 \mathrm{~h}$ and $t=4 \mathrm{~h}$, together with the direction of regulation (up or down), of the differentially expressed genes obtained by microarray analysis in the barrel cortex after enriched environment. Genes are ordered by significance (most significant genes on top). Only well-annotated genes are included.

solution (30\% ethyleneglycol, $20 \%$ glycerol in sodium phosphate buffer, $\mathrm{pH}$ 7.3) until additional analysis.

RNA isolation. Tissue samples were homogenized with a TissueLyser (Retsch $\mathrm{GmbH}$ ) in TRIzol Reagent (Invitrogen), according to the protocol of the manufacturers. The procedure was modified for small amounts of tissue by using $800 \mu \mathrm{l}$ of TRIzol Reagent and adding $1 \mu \mathrm{l}$ of glycogen (Fermentas). RNA concentration and quality was determined with a NanodropTM ND-1000 spectrophotometer (Thermo Fisher Scientific) and $1 \%$ agarose gel electrophoresis, respectively. The samples were kept at $-80^{\circ} \mathrm{C}$ until additional analysis.

Microarray analysis. Samples from UNCLIP groups (with and without EE) were processed for microarray analysis. To reduce variability, RNA samples were pooled (three samples per pool), resulting in 12 pools (two to four pools per experimental group). The pooled samples were purified with the NucleoSpin RNA II kit (Macherey-Nagel GmbH \& Co.) and sent to ServiceXS BV for additional processing. Sample concentration and integrity was checked with a Bioanalyzer 2100 (Agilent Technologies), followed by labeling using the Affymetrix Transcript (WT) SingleStranded Target Labeling kit, hybridization to the GeneChip Rat Gene 1.0 ST Array (both from Affymetrix), and scanning. The Affymetrix Command Console and Expression Console software were used for the performance of the washing, staining, and scanning of the chips. Data quality controls were within Affymetrix specifications.

Normalization of the microarray data was performed with GeneSpring GX version 11 (Agilent Technologies). The raw data were summarized using ExonRMA as a summarization algorithm, followed by log and baseline transformation to the median of all the samples. After transformation, data were filtered on expression (20-100th percentile). Normalized data were analyzed by Significance Analysis of Microarrays (SAM) as described previously (Tusher et al., 2001), using the "samr" package (http://www-stat.stanford.edu/ tibs/SAM) in R version 2.12.0 (http:// www.r-project.org). Criteria for differential expression were a $p$ value $\leq 0.05$ (delta 2.05) and a fold change (FC) $\geq|1.2|$. Gene ontology (GO) enrichment analysis of the differentially expressed genes was performed using the Web-based gene ontology tool from the Database for Annotation, Visualization, and Integrated Discovery (DAVID) version 6.7 (http://david.abcc.ncifcrf.gov) (Dennis et al., 2003; Huang et al., 2009). This analysis was performed by using the Functional Annotation Chart (in which GO enrichment in the list of differentially expressed genes is tested) and the Functional Annotation Clustering tool (which groups redundant GO terms in clusters to facilitate the interpretation of the results). For the enrichment analysis (Functional Annotation Chart tool), default software settings were used, and GO terms with a $p$ value [or EASE score (for Expression Analysis Systematic Explorer)] $\leq 0.05$ were considered to be overrepresented (enriched). For the Functional Annotation Clustering tool, the classification stringency was set as high, and only clusters with an enrichment score $\geq 1.3$ (equivalent to non-log scale $p$ of 0.05 ) were considered.

Quantitative PCR. Before cDNA synthesis, $2 \mu \mathrm{g}$ of each RNA sample was treated with $2 \mathrm{U}$ of DNase (Fermentas) in the presence of RiboLock RNase Inhibitor $(20 \mathrm{U} / \mu \mathrm{l})$ (Fermentas). For cDNA synthesis, through random priming, the RevertAid H Minus First Strand cDNA Synthesis kit (Fermentas) was used, following the guidelines of the manufacturer. Before analysis, $15 \mu \mathrm{l}$ of each cDNA sample was diluted with $185 \mu \mathrm{l}$ of MilliQ water. qPCR reactions were performed with the Rotor-Gene 6000 Series (Corbett Life Science Pty. Ltd.). For each reaction, $2.5 \mu \mathrm{l}$ of each diluted sample of cDNA was added to a mix containing $6.25 \mu$ l of $2 \times$ Maxima SYBR Green qPCR Master Mix (Fermentas), $1 \mu$ l of each primer $(5 \mu \mathrm{M})$, and $1.75 \mu \mathrm{l}$ of MilliQ water. Primers were designed using NCBI Primer-Blast (www.ncbi.nlm.nih.gov/tools/primer-blast/) and synthe- 
Table 4. Functional clusters of enriched GO categories (most significant category of each cluster shown)

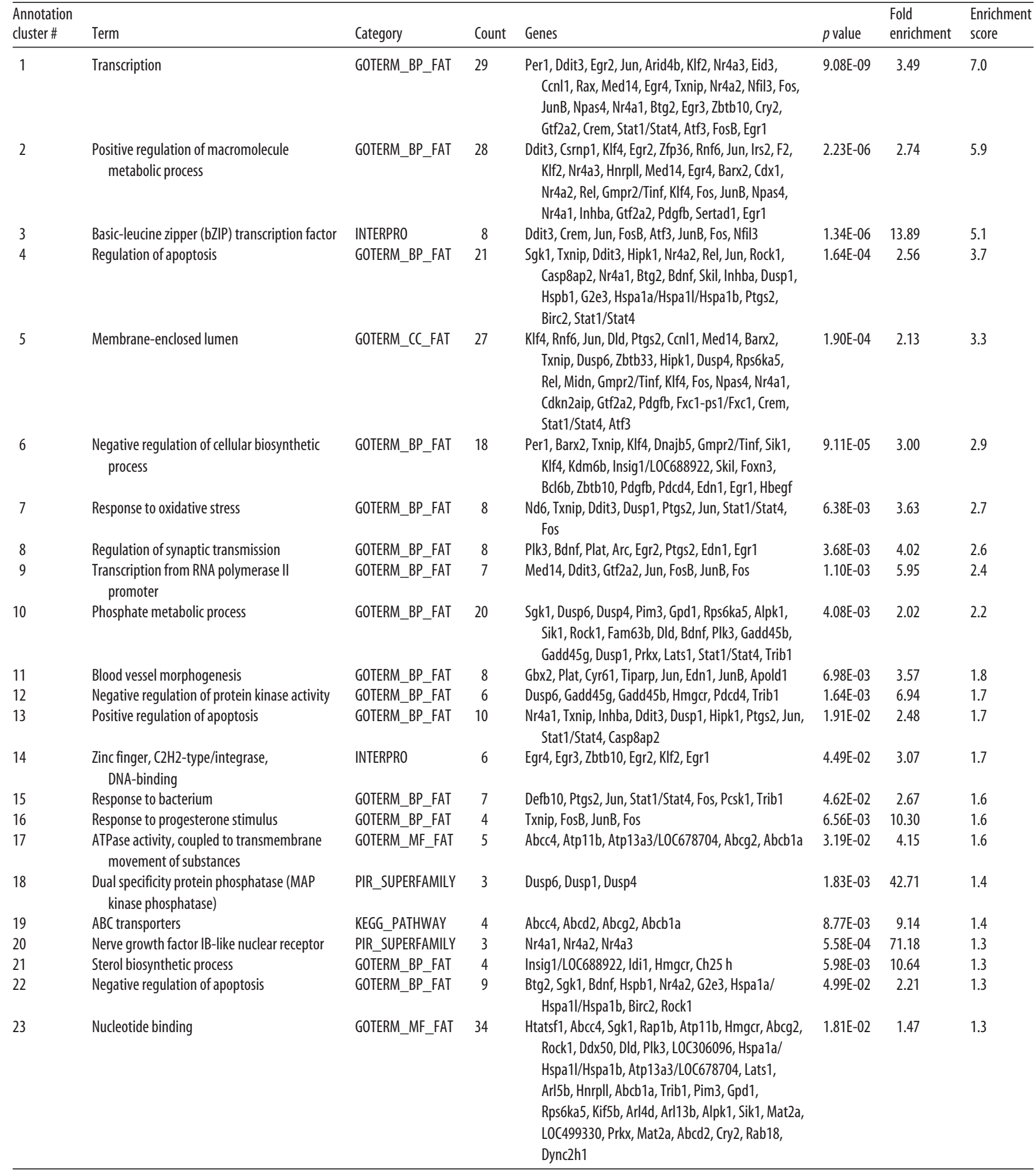

Shown are the different functional clusters of significantly enriched G0 categories of the differentially expressed genes. For each cluster, the term, category, count, and genes (Gene symbol) are shown, together with the $p$ value and the fold enrichment.

sized at Biolegio BV. Primer sequences are listed in Table 1. Cycling conditions were $10 \mathrm{~min} 95^{\circ} \mathrm{C}$, followed by 40 cycles of $15 \mathrm{~s}$ at $95^{\circ} \mathrm{C}, 30 \mathrm{~s}$ at $60^{\circ} \mathrm{C}$, and $30 \mathrm{~s}$ at $72^{\circ} \mathrm{C}$. After cycling, a melting protocol was performed, from $72^{\circ} \mathrm{C}$ to $95^{\circ} \mathrm{C}$, measuring fluorescence every $1^{\circ} \mathrm{C}$, to control for product specificity.

Relative expression of the genes of interest was calculated after obtaining the corresponding Ct values and correcting for unequal sample input using geNorm (Vandesompele et al., 2002), which identifies the two most stably expressed housekeeping genes (Ywhaz and $C y c A$ ) from a set of three tested candidate genes reported previously to be stably expressed in the brain (Bonefeld et al., 2008) to calculate a normalization factor for each sample. This normalization factor was then used to obtain the relative differences between the samples for each primer pair. Statistics were performed using SPSS 17.0 (SPSS Inc.). Normalized data were tested 
Table 5. Significantly overrepresented pathways

\begin{tabular}{|c|c|c|c|c|c|c|}
\hline Pathway\# & Term & Category & Count & Genes & $p$ value & $\begin{array}{l}\text { Fold } \\
\text { enrichment }\end{array}$ \\
\hline 1 & MAPK signaling pathway & KEGG_PATHWAY & 16 & $\begin{array}{l}\text { Rap1b, Dusp6, Ddit3, Dusp4, Rps6ka5, Jun, Fos, } \\
\text { Nr4a1, Bdnf, Hspb1, Gadd45g, Dusp1, Gadd45b, } \\
\text { Prkx, Hspa11, Pdgfb }\end{array}$ & $2.20 \mathrm{E}-08$ & 5.98 \\
\hline 2 & Platelet-derived growth factor receptor signaling pathway & GOTERM_BP_FAT & 5 & Txnip, Plat, Csrnp1, Tiparp, Pdgfb & $1.41 \mathrm{E}-04$ & 18.14 \\
\hline 3 & Enzyme linked receptor protein signaling pathway & GOTERM_BP_FAT & 12 & $\begin{array}{l}\text { Txnip, Skil, Plat, Csrnp1, Tiparp, Pdgfb, Jun, Tob1, } \\
\text { Fos, Dok1, Irs2, Hbegf }\end{array}$ & $5.43 \mathrm{E}-04$ & 3.55 \\
\hline 5 & $\begin{array}{l}\text { Transmembrane receptor protein serine/threonine kinase } \\
\text { signaling pathway }\end{array}$ & GOTERM_BP_FAT & 5 & Skil, Pdgfb, Jun, Tob1, Fos & $1.82 \mathrm{E}-02$ & 4.93 \\
\hline 6 & Transforming growth factor $\beta$ receptor signaling pathway & GOTERM_BP_FAT & 4 & Skil, Pdgfb, Jun, Fos & $1.83 \mathrm{E}-02$ & 7.10 \\
\hline 7 & Neurotrophin signaling pathway & KEGG_PATHWAY & 5 & Rap1b, Bdnf, Rps6ka5, Jun, Irs2 & $3.63 \mathrm{E}-02$ & 3.90 \\
\hline
\end{tabular}

Shown are the pathways that were overrepresented from the $\mathrm{G} 0$ analysis of the differentially expressed genes. For each pathway, the term, category, count, and genes (Gene symbol) are shown, together with the $p$ value and the Fold enrichment.

A
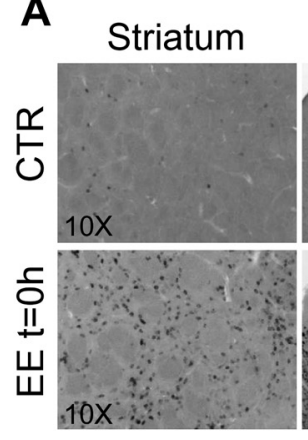

Barrel cortex

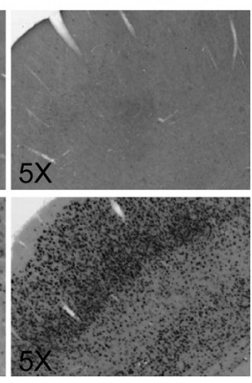

B

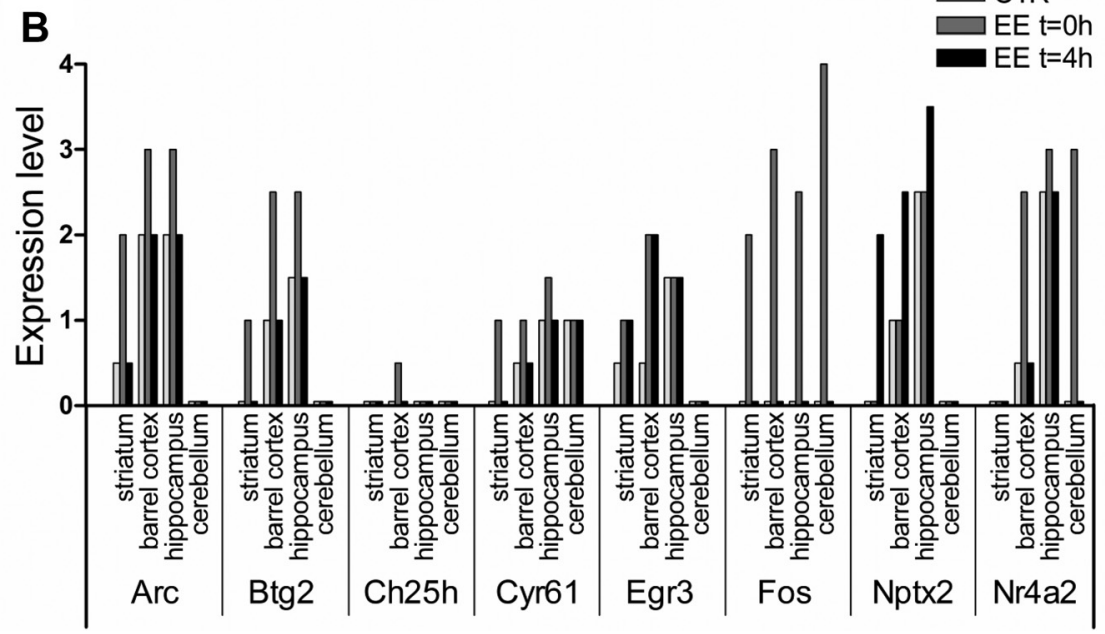

Figure 2. Representative brain areas activated by enrichment. $A$, Shown are representative images of Fos mRNA obtained by in situ hybridization in CTR and EE animals at $t=0 \mathrm{~h}$. In CTR animals, Fos levels were barely detectable, whereas in EE animals, increased levels were observed in striatum, barrel cortex, hippocampus, and cerebellum. Magnifications are shown at the bottom left corner on each image. B, Expression levels of the eight genes (Arc, Btg2, Ch25h, Cyr61, Egr3, Fos, Nptx2, and Nr4a2) selected for in situ hybridization were quantified in CLIP animals in the four above-mentioned brain areas, showing different regional and temporal patterns of expression under CTR and EE conditions.

for variance homogeneity using Levene's test, and, in case of nonhomogeneous data, a log transformation was applied. To directly compare the values (FC) obtained by microarray and qPCR analysis, a two-tailed Pearson's correlation was used. In addition, to compare expression levels between the different groups, univariate two-way ANOVAs were performed separately for each gene in the UNCLIP and CLIP groups, followed, when appropriate, by SNK post hoc analyses and independent samples $t$ tests, with a significance level of $p \leq 0.05$. To estimate the specificity of the changes in gene expression, we calculated a "specificity index" for each time point, defined as the ratio $A / B$, with $A$ being the difference in individual $\mathrm{EE}$ expression levels and average CTR expression levels in the spared [right (R)] cortical side (individual EE R - average CTR R) and $B$ being the difference in individual EE expression levels and average CTR expression levels in the deprived [left (L)] cortical side (individual EE L - average CTR L). This ratio was used to test with a one-sample $t$ test (test value 1 , significance level $p \leq 0.05$ ) whether expression levels in the spared (R) side were higher than in the deprived (L) side.

In situ hybridization. The plasmid containing the full-length rat activity-regulated cytoskeleton-associated protein $(A r c)$ cDNA subcloned into the EcoRI-XhoI site of pBluescriptII SK+ (Stratagene) was kindly provided by Dr P. F. Worley (John Hopkins University, Baltimore, $\mathrm{MD})$. The plasmid was linearized with EcoRI or XhoI and transcribed with T7 or SP6 RNA polymerases to generate antisense and sense probes, respectively. For the other genes, nested PCR was used to obtain DNA templates for sense and antisense probe generation of the gene of interest. Primers were designed using NCBI Primer-Blast (www.ncbi.nlm.nih.gov/tools/primer-blast/) and synthesized at Biolegio BV, adding T3 (5'AATTAACCCTCACTAAAGGG3') and T7 (5'TAATACGACTCACTATAGGG3') RNA polymerase sequences at the $5^{\prime}$ end of the forward and reverse internal primers, respectively (primer sequences are listed in Table 2). For the first (external) run, $3 \mu \mathrm{l}$ of cDNA was mixed with $1.6 \mu \mathrm{l}$ of each external primer (5 $\mu \mathrm{M}), 2 \mu \mathrm{l}$ of $10 \times$ PCR buffer, $0.2 \mu \mathrm{l}$ of dNTP mix, $0.1 \mu \mathrm{l}$ of Taq polymerase, and $11.5 \mu \mathrm{l}$ of DEPC water to a final volume of $20 \mu \mathrm{l}$ (all from Fermentas). The same components were used for the internal reaction, using a 1:100 dilution of the external run end product as a template and the internal primers. A touchdown protocol was used for both runs. To activate the enzyme, the mix was heated to $94^{\circ} \mathrm{C}$ for $2 \mathrm{~min}$ (hot start), followed by 10 cycles of $60 \mathrm{~s}$ at $94^{\circ} \mathrm{C}, 30 \mathrm{~s}$ at $68^{\circ} \mathrm{C}\left(-1^{\circ} \mathrm{C}\right.$ per cycle $)$, and $90 \mathrm{~s}$ at $72^{\circ} \mathrm{C}$. Subsequently, 30 cycles were added of $60 \mathrm{~s}$ at $94^{\circ} \mathrm{C}, 30 \mathrm{~s}$ at $58^{\circ} \mathrm{C}$, and $90 \mathrm{~s}$ at $72^{\circ} \mathrm{C}$, with a final step of $10 \mathrm{~min}$ at $72^{\circ} \mathrm{C}$. After the PCR reaction, the samples were separated on a $1 \%$ agarose gel, and the correct products were gel extracted using the QIAEX II 
A

\section{$\operatorname{Arc}$}

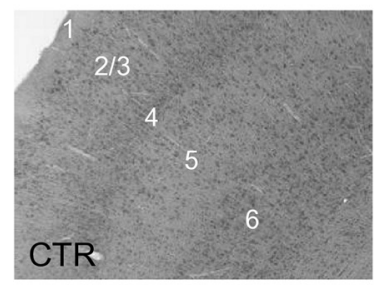

Btg2

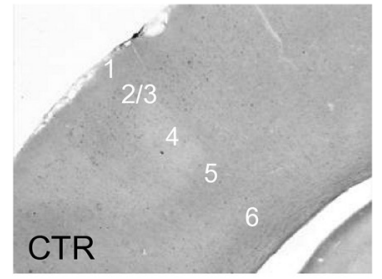

\section{Nr4a2}
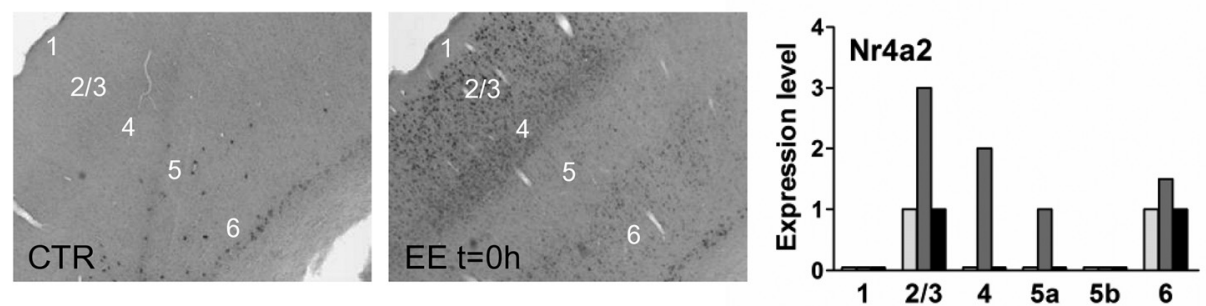

Nptx2
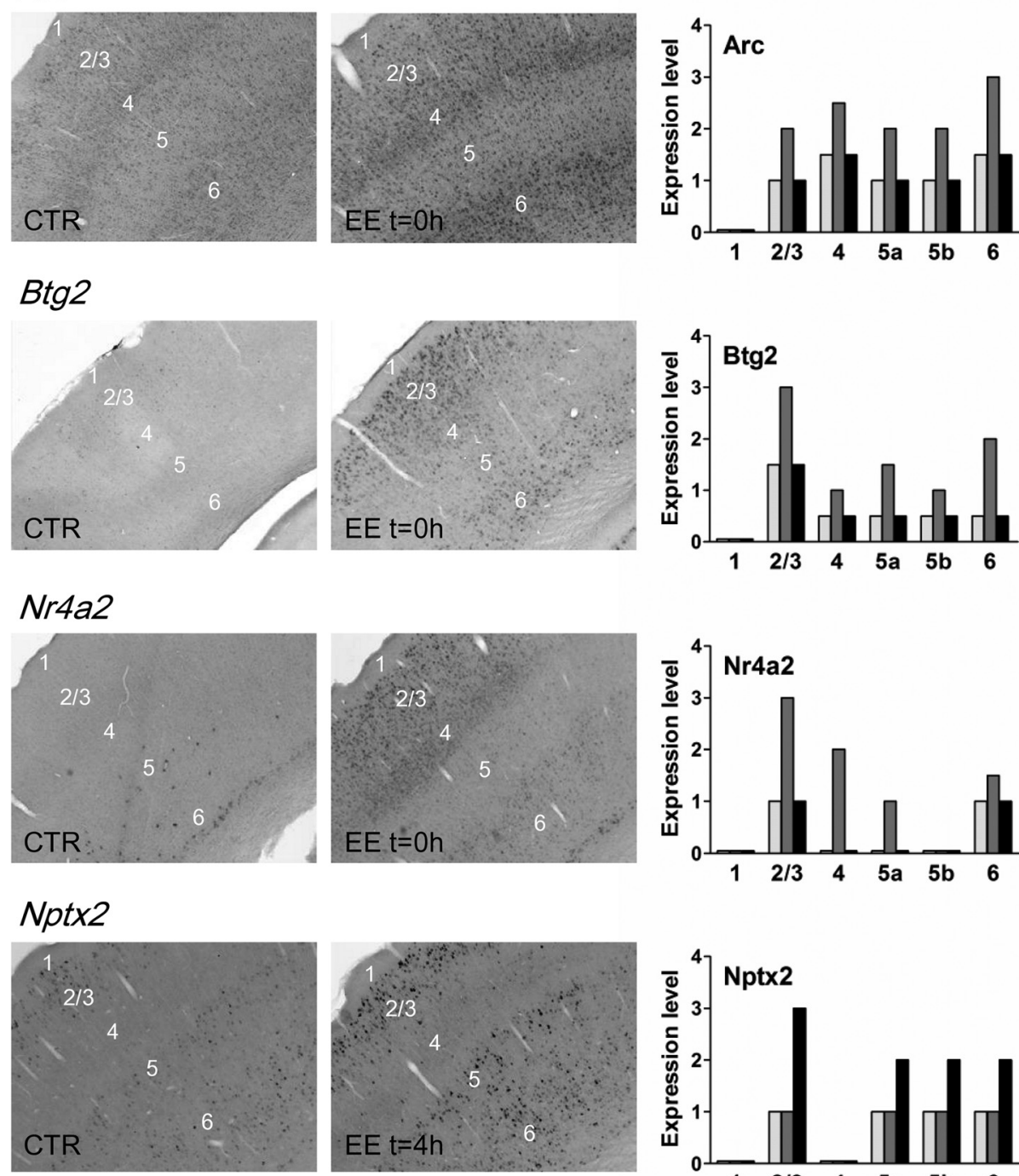

B
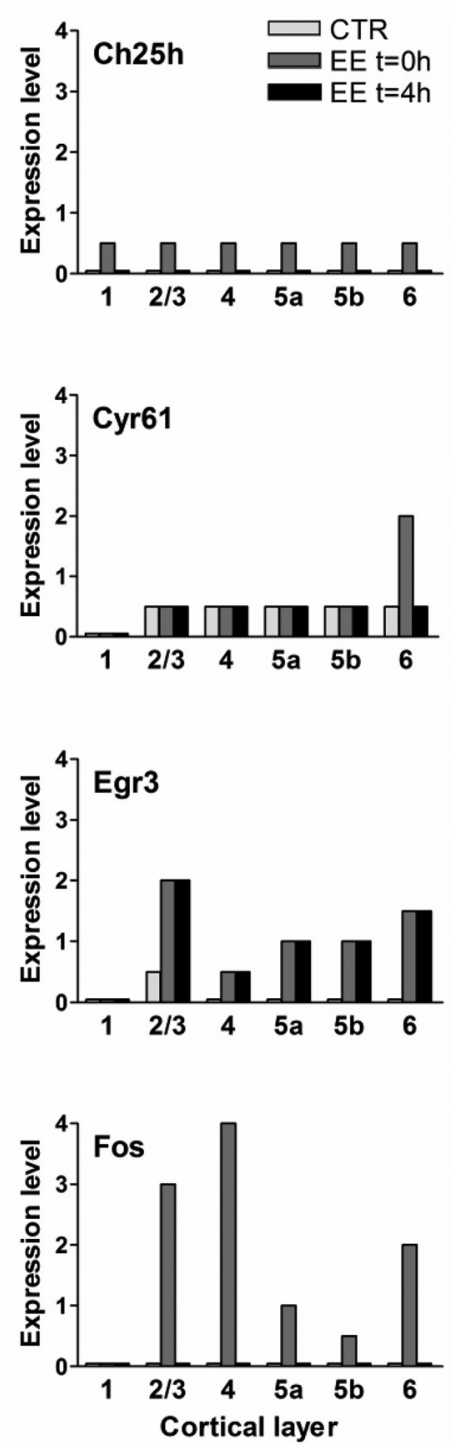

Figure 3. Layer-specific differential gene expression in rat barrel cortex after EE. $A$, Representative images of in situ hybridization analysis of Arc, Btg2, Nr4a2, and Nptx2 mRNA in UNCLIP groups: CTR and EE animals at $t=0 \mathrm{~h}(\mathrm{Arc}, \mathrm{Btg} 2, \mathrm{Nr} 4 a 2)$ or $t=4 \mathrm{~h}(\mathrm{Nptx2})$; cortical layers are indicated on each image (magnification, 5X). B, Quantification of Arc, Btg2, Nr4a2, Nptx2, Ch25h, Cyr61, Egr3, and Fos expression levels (in situ hybridization) in different cortical layers of UNCLIP animals, under CTR, EE $t=0 \mathrm{~h}$, and EE $t=4 \mathrm{~h}$ conditions.

kit (Qiagen Benelux BV), measuring their concentration with a Nanodrop ND-1000 spectrophotometer (Thermo Fisher Scientific).

Sense and antisense digoxigenin (DIG)-labeled probes were generated by in vitro transcription using SP6, T3, or T7 RNA polymerases, depending on the probe. The $20 \mu \mathrm{l}$ of mixture included $0.3-1 \mu \mathrm{g}$ of probe template, $1 \mathrm{~mm}$ each of ATP, CTP, and GTP, $0.7 \mathrm{~mm}$ UTP, $0.3 \mathrm{~mm}$ DIG-UTP (Roche Applied Science), 40 U of RiboLock RNase inhibitor, $1 \times$ transcription buffer, and $40 \mathrm{U}$ of SP6, T7, or T3 RNA polymerase (all from Fermentas). After $2 \mathrm{~h}$ incubation at $37^{\circ} \mathrm{C}$, the probe template was digested with $2 \mathrm{U}$ of RNase-free DNase I (Fermentas) for $15 \mathrm{~min}$ at $37^{\circ} \mathrm{C}$. The labeled cRNA probe was then precipitated overnight by adding $1 \mu \mathrm{l}$ of glycogen (Fermentas), $2.5 \mu \mathrm{l}$ of $4 \mathrm{M} \mathrm{LiCl}$, and $75 \mu \mathrm{l} 100 \%$ ethanol and recovered by centrifuging at $4^{\circ} \mathrm{C}$ for $15 \mathrm{~min}$. The pellet was washed twice and resuspended in $25 \mu \mathrm{l}$ of DEPC $\mathrm{H}_{2} \mathrm{O}$. The amount of labeled probe was quantified by spot blot using DIG-labeled control RNA of known concentration (Roche Applied Science) for comparison. The resulting DIG-labeled probes were stored in nuclease free water at $-20^{\circ} \mathrm{C}$.

In situ hybridization was performed in free-floating tissue sections using DIG-labeled riboprobes as described previously (Schaeren-

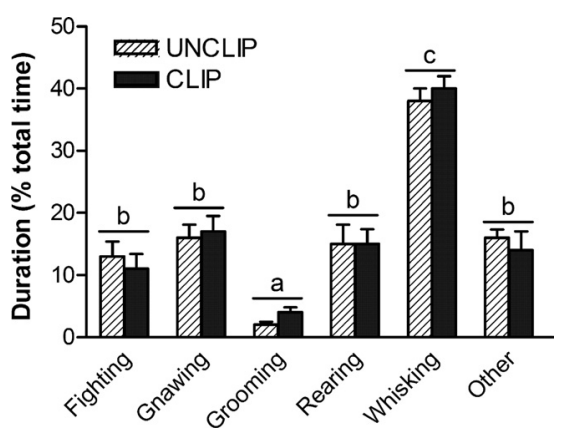

Figure 4. Behavioral analysis of UNCLIP and CLIP animals during exposure to EE. Shown is the amount of time that the animals displayed a certain behavior (namely, fighting, gnawing, grooming, rearing, whisking, and other behaviors). The measurements were performed during a period of $10 \mathrm{~min}$, starting $10 \mathrm{~min}$ after the beginning of the EE exposure, in both UNCLIP and CLIP animals (white and gray bars, respectively). Bars represent average \pm SEM ( $n=6-8)$. Homogeneous subsets are indicated with the same characters $(\boldsymbol{a}-\boldsymbol{c})$ above the bars (two-way ANOVA, $p \leq 0.001$; post hoc SNK test). 

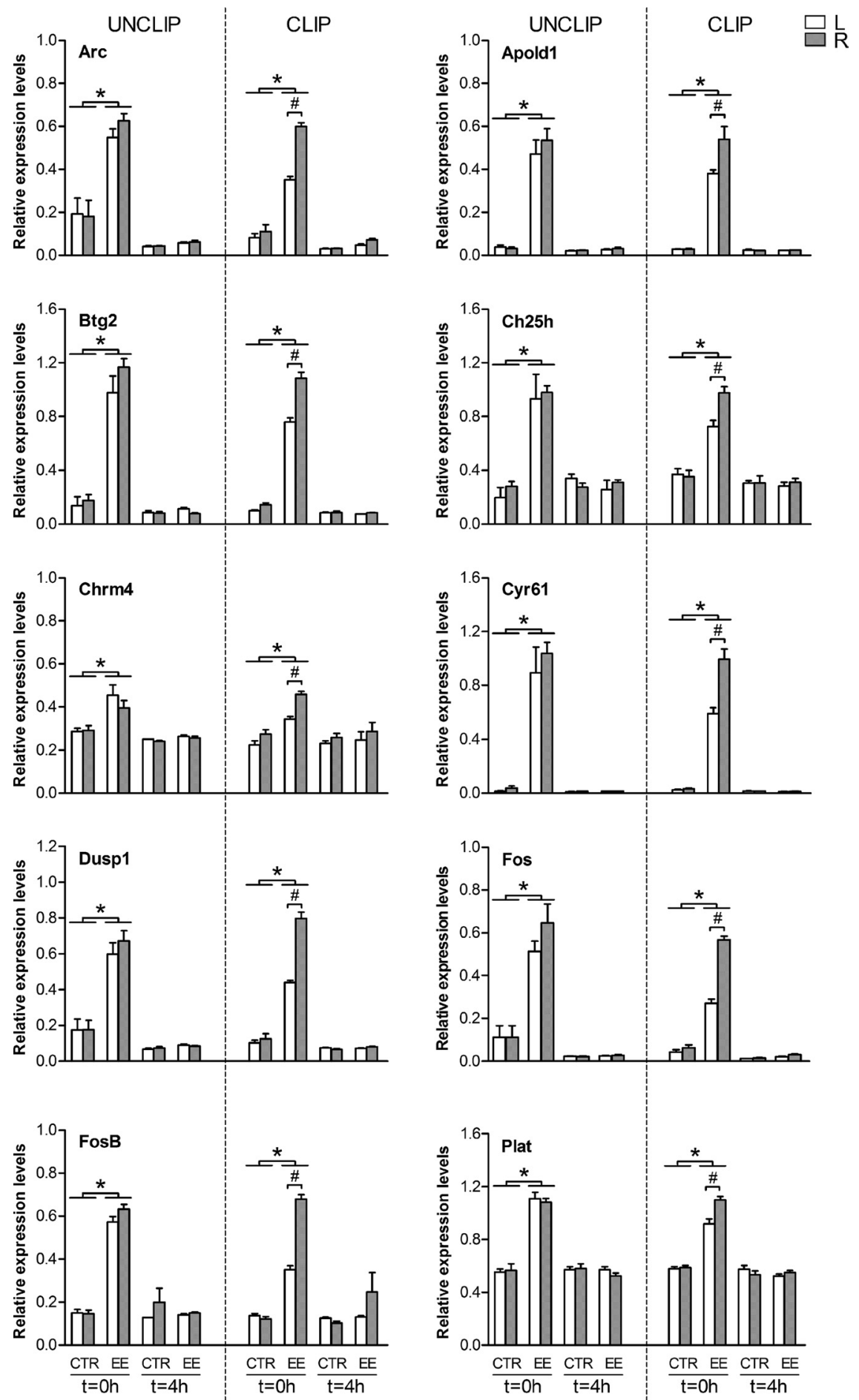

Figure 5. $q \mathrm{PCR}$ analysis of gene expression in the rat barrel cortex after EE. Normalized expression values of $A r c, A p o l d 1$, Btg2, Ch25h, Chrm4, Cyr61, Dusp1, Fos, FosB, and Plat mRNA at $t=0 \mathrm{~h}$ and $t=4 \mathrm{~h}$ after exposure to EE for $30 \mathrm{~min}$, in UNCLIP (right group of bars) and CLIP (left group of bars) animals. For normalization, $C y C A$ and $Y w h a z$ were selected as housekeeping genes. Measurements were made separately for left ( $L$, white bars) and right ( $R$, gray bars) barrel cortices. Note that, in CLIP groups, L barrel cortex is deprived of sensory input attributable to unilateral clipping of the right whiskers. Bars represent average normalized expression values \pm SEM. ${ }^{*}$ represents significant differences between CTR and EE groups (two-way ANOVA, $p \leq 0.05$; post hoc SNK test). \# represents significant differences between $\mathrm{L}$ and $\mathrm{R}$ barrel cortices within the same group and time point ( $p \leq 0.05$, Student's $t$ test). In the deprived (L) barrel cortex of CLIP animals, for all analyzed genes, expression levels were significantly higher in EE than in CTR groups at $t=0 \mathrm{~h}$, indicative of residual activation in the deprived cortex ( $p \leq 0.05$, Student's $t$ test); for the sake of clarity, these significant differences have not been marked by a symbol in the figure.
Wiemers and Gerfin-Moser, 1993; Korosi et al., 2006), with minor modifications. All the steps were performed under RNase-free conditions and at room temperature unless stated otherwise. Throughout the procedure, the sections were kept under gentle agitation in sixwell plates using Netwells (both from Corning Inc.). Briefly, sections were washed in PBS followed by a $30 \mathrm{~min}$ postfixation with $4 \%$ PFA in 0.1 м Borax. Next, sections were permeabilized with $0.2 \mathrm{M} \mathrm{HCl}$, washed in PBS, and treated with $0.01 \mathrm{mg} / \mathrm{ml}$ proteinase $\mathrm{K}$ (Roche Applied Science) in $0.1 \mathrm{~m}$ Tris, $0.05 \mathrm{~m}$ EDTA buffer, $\mathrm{pH}$ 8.0 , for $15 \mathrm{~min}$ at $37^{\circ} \mathrm{C}$. The sections were acetylated with $0.1 \mathrm{~m}$ TEA containing $0.25 \%$ acetic anhydride (Sigma-Aldrich), followed by overnight incubation at $58^{\circ} \mathrm{C}$ in hybridization buffer [50\% deionized formamide (Ambion), $1 \times$ Denhardt's solution and $10 \%$ dextran sulfate (both from Sigma-Aldrich), $0.5 \mathrm{mg} / \mathrm{ml}$ tRNA (Roche Applied Science), $0.3 \mathrm{M} \mathrm{NaCl}, 1$ mM EDTA, and $10 \mathrm{~mm}$ Tris, $\mathrm{pH}$ 8.0] containing $1 \mathrm{ng} / \mathrm{ml}$ of the DIG-labeled probe. The next day, sections were washed in $4 \times$ SSC and treated with $0.01 \mathrm{mg} / \mathrm{ml} \mathrm{RNase} \mathrm{A} \mathrm{(Sigma-}$ Aldrich) in $0.5 \mathrm{M} \mathrm{NaCl}, 0.01 \mathrm{~m}$ Tris, and $1 \mathrm{~mm}$ EDTA buffer, $\mathrm{pH} 8.0$, for $15 \mathrm{~min}$ at $37^{\circ} \mathrm{C}$ for 30 min at $37^{\circ} \mathrm{C}$, followed by washing steps in decreasing concentrations of SSC, including a 30 min wash in $0.1 \times S S C$ at $58^{\circ} \mathrm{C}$, several rinses in TBS, and $1 \mathrm{~h}$ blocking [ $0.05 \%$ blocking reagent (Roche Applied Science) in TBS]. Sections were then incubated for $3 \mathrm{~h}$ with sheep anti-DIG-AP (1:5000; Roche Applied Science), followed by several rinses in alkaline phosphatase (AP) buffer (50 $\mathrm{mm} \mathrm{MgCl}_{2}$ in TBS, $\mathrm{pH}$ 9.5) and overnight incubation with nitroblue-tetrazolium-chloride/ 5-bromo-4-chlor-indolyl-phosphate (NBT/ BCIP) medium [175 $\mu$ l NBT/BCIP stock solution (Roche Applied Science) in $10 \mathrm{ml}$ of AP buffer, containing $0.24 \mathrm{mg} / \mathrm{ml}$ levamisole] in the dark. Staining was stopped by several washes in $0.1 \mathrm{M}$ Tris, $0.01 \mathrm{~m}$ EDTA buffer, $\mathrm{pH}$ 8.0, and sections were mounted on Superfrost Plus slides (Thermo Fisher Scientific), air dried, dehydrated in increasing ethanol concentrations, fixed briefly with isopropanol and acetone, cleared in xylene, and coverslipped with Entellan (Merck Chemicals). The sections were examined under a Leica DM 6000B microscope and representative pictures captured with a Leica DFC480 CCD camera using Leica IM500 imaging software (Leica Microsystems). In addition, a qualitative analysis was performed by a blind observer to determine expression levels, ranked as undetectable (0), low (1), medium (2), high (3), and very high (4), in various brain regions (striatum, cortex, hippocampus, and cerebellum) and in the different cortical layers.

\section{Results}

Microarray analysis reveals differentially expressed genes in rat barrel cortex after in vivo somatosensory experience

To study experience-dependent changes in mRNA expression at the level of the 

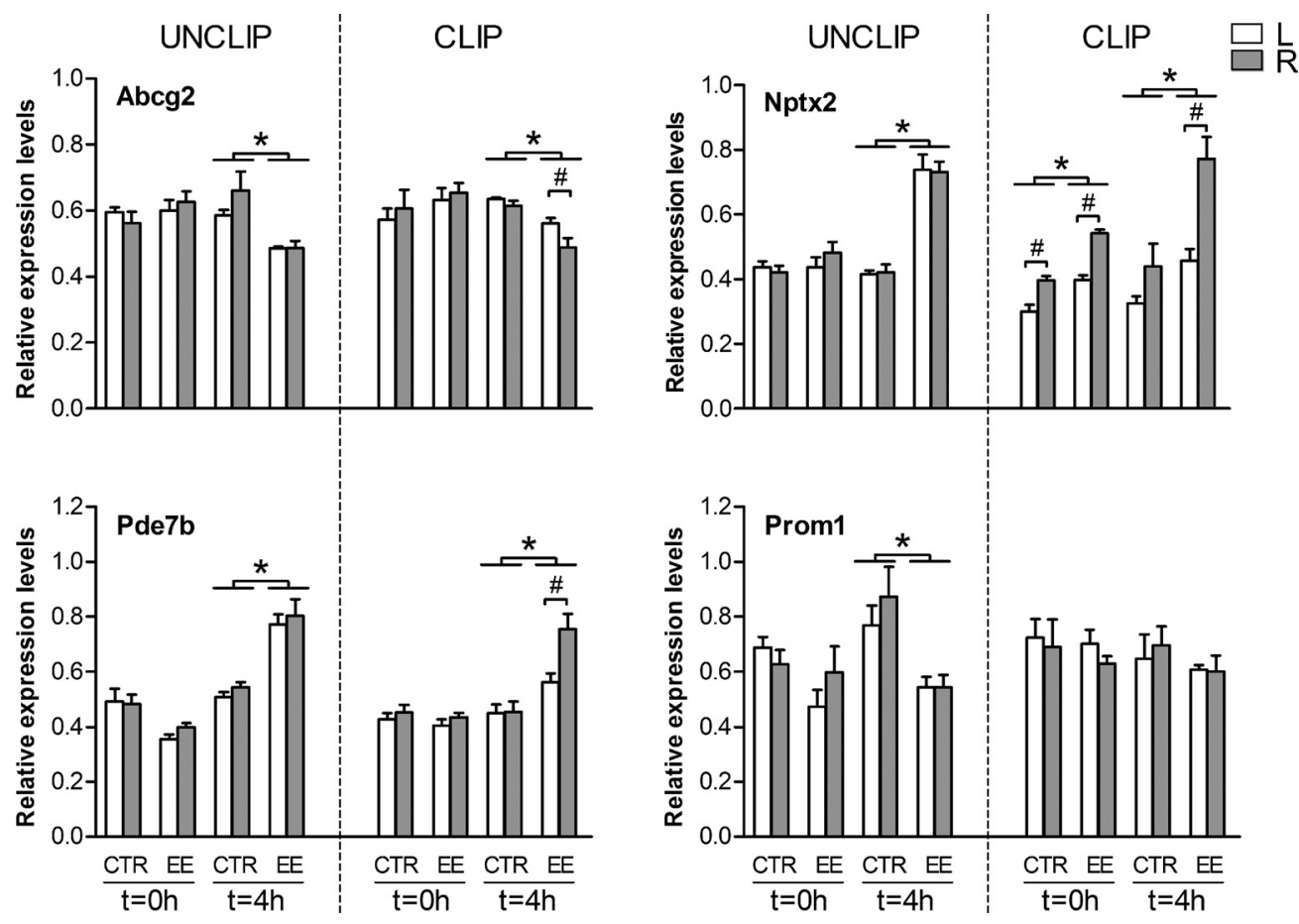

Figure 6. qPCR analysis of gene expression in the rat barrel cortex after EE. Normalized expression values of $A b c g 2, N p t x 2, P d e 7 b$, and Prom $1 \mathrm{mRNA}$ in rat somatosensory cortex at $t=0 \mathrm{~h}$ and $t=$ 4 hafter exposure to EE for $30 \mathrm{~min}$, in UNCLIP (right group of bars) and CLIP (left group of bars) animals. For normalization, Cyc $A$ and $Y$ whaz were selected as housekeeping genes. Measurements were made separately for left (L, white bars) and right ( $R$, gray bars) barrel cortices. Note that, in CLIP groups, L barrel cortex is deprived of sensory input attributable to unilateral clipping of the right whiskers. Bars represent average normalized expression values \pm SEM. ${ }^{*}$ represents significant differences between (TR and EE groups (two-way ANOVA, $p \leq 0.05$; posthoc SNK test). \# represents significant differences between left and right barrel cortices within the same group and time point ( $p \leq 0.05$, Student's t test). In the deprived (L) barrel cortex of CLIP animals, for all analyzed genes, expression levels were significantly higher in EE than in CTR groups at $t=4 \mathrm{~h}$, except for Prom 1 , indicative of residual activation in the deprived cortex ( $p \leq 0.05$, Student's $t$ test); for the sake of clarity, these significant differences have not been marked by a symbol in the figure.

barrel cortex, adult rats were placed in the dark, per two, in an enriched cage during a short $(30 \mathrm{~min})$ period. The animals had been habituated previously to the empty test cages to minimize stress-induced artifacts. In contrast to caged-control (CTR) animals, EE exposure induced strong exploratory behavior, especially through active whisking. Importantly, stress-induced behaviors such as self-grooming (Spruijt et al., 1992) were hardly observed, indicating that the habituation procedure successfully reduced novelty-associated stress.

To determine which genes were differentially expressed in the barrel cortex after EE, mRNA expression profiling was performed using microarrays. Expression levels were determined at two time points after the EE session, namely 0 and $4 \mathrm{~h}$, and compared with those observed in CTR rats. Significant differences in gene expression were observed at both time points after EE compared with the respective CTR groups, with 170 genes upregulated and 31 downregulated at $t=0 \mathrm{~h}$ and 29 upregulated and 98 downregulated genes at $t=4 \mathrm{~h}$ (Table 3 ). Of all the differentially expressed genes, 40 were identified at both time points after EE.

\section{Validation of microarray results by qPCR analysis}

To validate our results, we verified the differential expression of a subset of genes by qPCR analysis. The genes were selected on the basis of their functional annotation (a wide range of biological functions was chosen, including transcription factor activity, nuclear receptors, cholesterol metabolism, and regulation of synaptic plasticity). A total of 18 genes, ranging from low to high FC and $p$ values, were selected for validation, together with three housekeeping gene candidates for normalization (for a list of selected genes and primer pairs, see Table 1). To estimate the validation rate, the normalized expression levels obtained by qPCR (normalized against CycA and Rywhaz as the two most stable housekeeping genes) were used to calculate an FC for each time point, similar to the microarray analysis (i.e., EE vs CTR at $t=0 \mathrm{~h}$ and $t=4 \mathrm{~h}$ ). The FCs obtained by the microarray and qPCR analyses were highly correlated (Pearson's correlation, two-tailed, $r^{2}=0.992, p \leq 0.0001$ at $t=0 \mathrm{~h}$ and $r^{2}=0.927, p \leq$ 0.001 at $t=4 \mathrm{~h}$ ), strongly supporting the validity of the criteria used for the microarray data analysis. In summary, these results show that the expression of a number of genes is modified by increased sensory exploration in the rat barrel cortex, the majority of genes being upregulated at $t=0 \mathrm{~h}$ and downregulated at $t=4 \mathrm{~h}$.

\section{Overrepresented GO categories of the differentially expressed genes}

The observed massive EE-induced regulation of gene expression in the barrel cortex suggests that a short but intense period of sensory experience is able to trigger major cellular changes, which could potentially lead to changes in neuronal circuits. To classify these changes, we used a GO enrichment and functional clustering analysis [DAVID version 6.7 (Dennis et al., 2003; Huang et al., 2009)] as a tool to test whether particular functional categories were overrepresented (enriched) in our dataset. From the list of differentially expressed genes (both at $t=0 \mathrm{~h}$ and $t=4 \mathrm{~h}$ ), as much as 249 significantly overrepresented GO terms were identified, using as a background list all genes present on the array (modified Fisher's exact test, EASE score $\leq$ 0.05). These GO terms were grouped into 23 functional clusters (DAVID Fuzzy clustering, enrichment score $\geq 1.3$ ), including regulation of cel- 

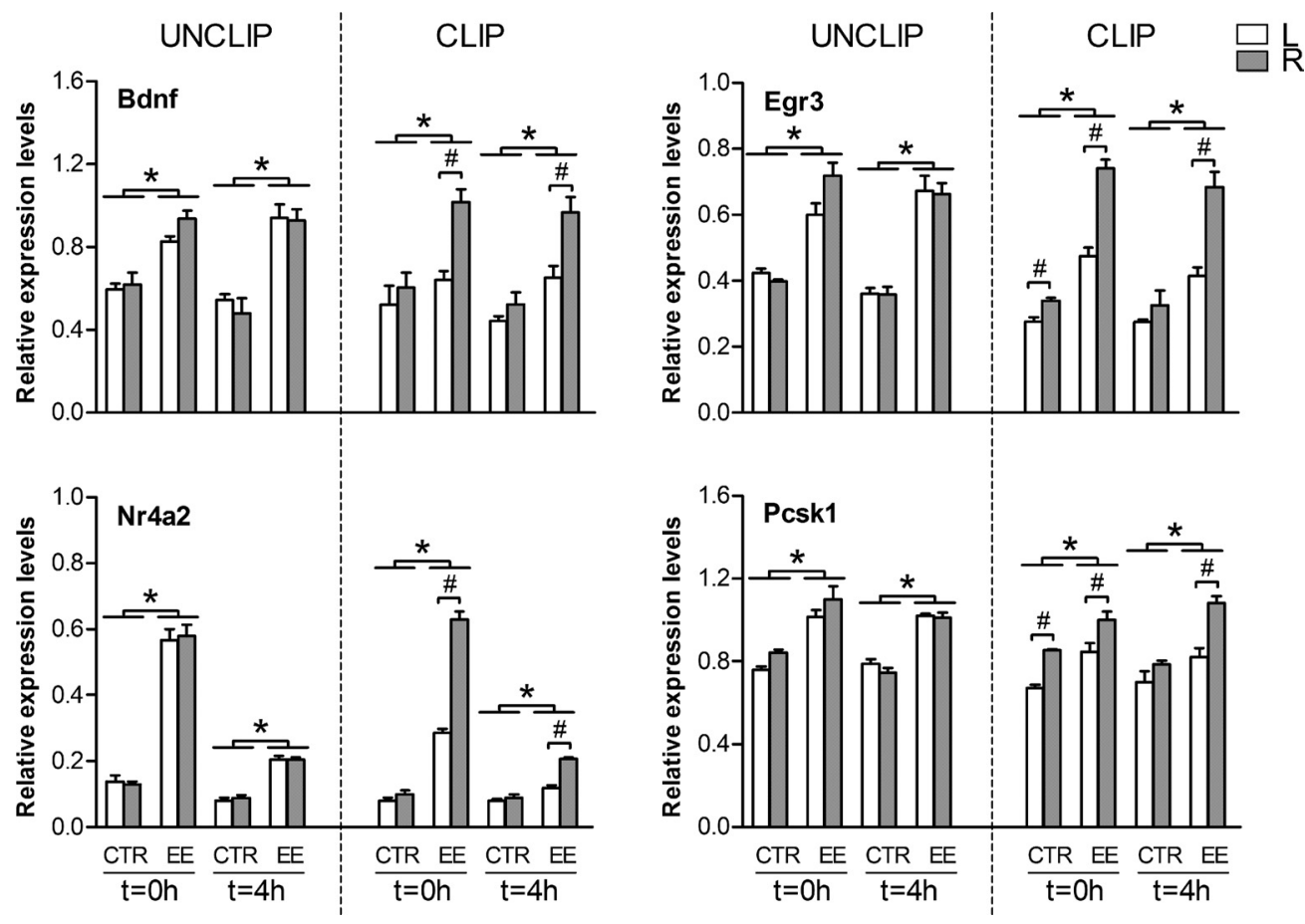

Figure 7. qPCR analysis of gene expression in the rat barrel cortex after EE. Normalized expression values of $B d n f, E g r 3, N r 4 a 2$, and $P c s k 1 \mathrm{mRNA}$ in rat somatosensory cortex at $t=0 \mathrm{~h}$ and $t=$ 4 hafter exposure to EE for $30 \mathrm{~min}$, in UNCLIP (right group of bars) and CLIP (left group of bars) animals. For normalization, Cyc $A$ and $Y$ whaz were selected as housekeeping genes. Measurements were made separately for left (L, white bars) and right ( $R$, gray bars) barrel cortices. Note that, in CLIP groups, L barrel cortex is deprived of sensory input attributable to unilateral clipping of the right whiskers. Bars represent average normalized expression values \pm SEM. ${ }^{*}$ represents significant differences between (TR and EE groups (two-way ANOVA, $p \leq 0.05$; posthoc SNK test). \# represents significant differences between left and right barrel cortices within the same group and time point ( $p \leq 0.05$, Student'st test). In the deprived (L) barrel cortex of CLIP animals, for all analyzed genes, expression levels were significantly higher in EE than in CTR groups at $t=0 \mathrm{~h}$ and $t=4 \mathrm{~h}$, except for $B d n f$ at $t=0 \mathrm{~h}$ and $P$ csk 1 at $t=4 \mathrm{~h}$, indicative of some activation in the deprived cortex ( $p \leq$ 0.05 , Student's $t$ test); for the sake of clarity, these significant differences have not been marked by a symbol in the figure.

lular metabolic processes (nucleic acid, phosphate, and cholesterol metabolic processes), gene expression (transcription factors and nuclear receptors), apoptosis, synaptic plasticity, and blood vessel morphogenesis, among others (Table 4). Some signaling pathways were also overrepresented, such as the mitogenactivated protein kinase (MAPK) and the platelet-derived growth factor (PDGF) receptor signaling pathways (Table 5). With a similar analysis of 288 randomly selected genes ( 25 iterations), we obtained $29.9 \pm 10.7$ significantly enriched GO terms and $3.0 \pm$ 1.7 functional clusters, indicating a false-positive rate of $\sim 10 \%$. The GO enrichment and functional clustering analysis indicates that many of the EE-induced changes in gene expression are involved in general cellular processes, including cell growth and differentiation, regulation of transcription, and several metabolic processes. In addition, overrepresented clusters include functional categories related to synaptic plasticity, strongly linking our findings at the molecular level to EE-induced anatomical and physiological changes in rat barrel cortex (Fox, 2002; Polley et al., 2004).

\section{In situ hybridization of selected genes reveals cortical layer-specific patterning of mRNA expression}

To study the expression patterns of EE-induced genes at the cellular level, in situ hybridization was performed for selected genes. This information will reveal in which cortical layers these genes are expressed and, more specifically, link the time-specific induction of these genes with specific locations in the cortical network of the barrel cortex. From the list of differentially expressed genes, we selected nine differentially expressed genes based on (1) qPCR validation, (2) strong regulation on EE (high FC), (3) different peaks of activation ( $0 \mathrm{~h}, 4 \mathrm{~h}$, or both time points), and (4) different functional annotations. Included were genes previously known to be involved in neuronal plasticity and neuronal activation, such as the transcription factors Fos and Egr3, the cytoskeletal protein $A r c$, the nuclear factor Nr4a2, and the protein neuronal pentraxin 2 (Nptx2, also known as Narp, for neuronal activity-regulated protein). In addition, the vascular-related protein apolipoprotein $\mathrm{L}$ domain containing 1 (Apold1, also known as Verge, for vascular early response gene protein), the antiproliferative protein Btg2, the enzyme Ch25h (cholesterol metabolism), and the heparin-binding protein cysteine-rich angiogenic inducer 61 (Cyr61) were selected for in situ hybridization analysis.

The immediate-early gene and transcription factor Fos has been used extensively as a marker of neuronal activation (Sheng and Greenberg, 1990; Curran and Morgan, 1995). We used this marker to examine the main brain areas that were activated on $\mathrm{EE}$ exposure at $t=0 \mathrm{~h}$. In addition to cerebral cortex, we found evidence of activity in striatum, hippocampus, and cerebellar cortex, all areas strongly associated with locomotor activity and spatial learning (Fig. 2). Interestingly, in stress-related areas such as the hypothalamic paraventricular nucleus and the amygdala, the Fos transcript was undetectable (data not shown), indicating low stress levels in these animals (most likely because of the habituation of the animals preceding $\mathrm{EE}$ ). In addition, we investigated the expression of the other eight selected genes in cerebral cortex, striatum, hippocampus, and cerebellum (Fig. 2). Unfortunately, Apold 1 expression was below detection levels (data not shown); note that detection of Apold1 also failed in the Allen Mouse Brain Atlas (Lein et al., 2007). For the remaining seven 
genes, specific expression was detected in at least one of the time points studied, and all negative controls (sense probes) failed to detect any specific signal. Interestingly, whereas all seven genes were responsive to $\mathrm{EE}$ in the cerebral (barrel) cortex, each gene had a specific expression pattern in the other brain areas. Some genes (Arc, Btg2, Cyr61, and Nptx2) were upregulated in all areas except cerebellum, $\mathrm{Nr} 4 a 2$ in all areas except striatum, Egr3 in striatum and cortex, and Ch25h in cortex only.

We next focused on the patterns of mRNA expression of the selected genes in the different cortical layers of the barrel cortex (Fig. 3). Fos and Ch25h were undetectable in CTR groups; Fos was rapidly and strongly upregulated after $\mathrm{EE}$ at $t=0 \mathrm{~h}$, whereas $C h 25 h$ levels increased only slightly at this time point. Interestingly, Fos levels were primarily increased in layers $2 / 3$ and 4 and less in layers 5 and 6, whereas Ch25h levels increased similarly in all cortical layers. The two genes returned to basal (undetectable) levels at $t=4 \mathrm{~h}$. Expression of Btg2, Cyr61, Egr3, and Nr4a2 was barely detectable in CTR animals; only residual to low levels in scattered cells were detected primarily in layer 2/3 (Btg2, Egr3), layer 6 (Cyr61), or both layers $2 / 3$ and $6(\mathrm{Nr} 4 a 2)$. EE-induced upregulation of Egr 3 was observed at both $t=0 \mathrm{~h}$ and $t=4 \mathrm{~h}$ and took place primarily in layers $2 / 3$ and 6 and to a lesser extent in layers 4 and 5. In contrast, Btg2 and Cyr61 and Nr4a2 were only upregulated at $t=0 \mathrm{~h}$. At this time point, Btg2-positive cells increased in layers $2 / 3,6$, and, to a lesser extent, 4 and 5 , whereas Cyr61 increased primarily in layer 6. Nr4a2 was strongly increased in layers $2 / 3$ and 4 and less in layers 5 and 6 . The plasticity-related genes Arc and Nptx2 displayed a clear expression already in the CTR groups. Whereas Arc was primarily expressed in layers 4 and 6 and less in layers $2 / 3$ and 5, Nptx2 levels were detected to an equal extent in layers $2 / 3,5$, and 6 . During EE exposure, Arc levels were upregulated in all cortical layers, except layer 1 at $t=0 \mathrm{~h}$, and returned to basal levels at $t=4 \mathrm{~h}$. In contrast, $N p t x 2$ levels did not increase during EE at $t=0 \mathrm{~h}$ but did increase dramatically at $t=4 \mathrm{~h}$, especially in layer $2 / 3$ and also layers 5 and 6 .

Expression levels were comparable in both brain hemispheres for all the expression patterns described above. In summary, the in situ hybridization results show time- and layer-specific molecular changes related to experience-induced plasticity in the barrel cortex.

\section{EE-induced mRNA expression changes in the barrel cortex} are attributable to differential somatosensory processing

Because EE is known to induce plasticity in the entire brain, we investigated whether the changes in mRNA expression at the level of the barrel cortex reflected specific modifications in somatosensory processing or simply reflected general cortical activation. For this purpose, we performed experiments not only in rats without whisker manipulation (UNCLIP group) but also with rats in which the whiskers had been removed unilaterally $18 \mathrm{~h}$ before the EE session (CLIP group). Importantly, we performed a behavioral analysis showing that such a short time of deprivation did not affect exploratory behavior in CLIP animals because, similar to UNCLIP rats, CLIP animals spent most of the time actively whisking rather than displaying the other behaviors (two-way ANOVA, $p \leq 0.0001$; SNK) (Fig. 4), and they had no preference for a particular location in the test cage (data not shown). We then performed detailed qPCR analysis of the 18 differentially expressed and validated genes selected on the basis of the microarray results (see above) and compared the expression levels in the spared versus the deprived sides of the barrel cortex. The direction (up or down) and time point ( $t=0 \mathrm{~h}$ or $t=4 \mathrm{~h}$ ) of the
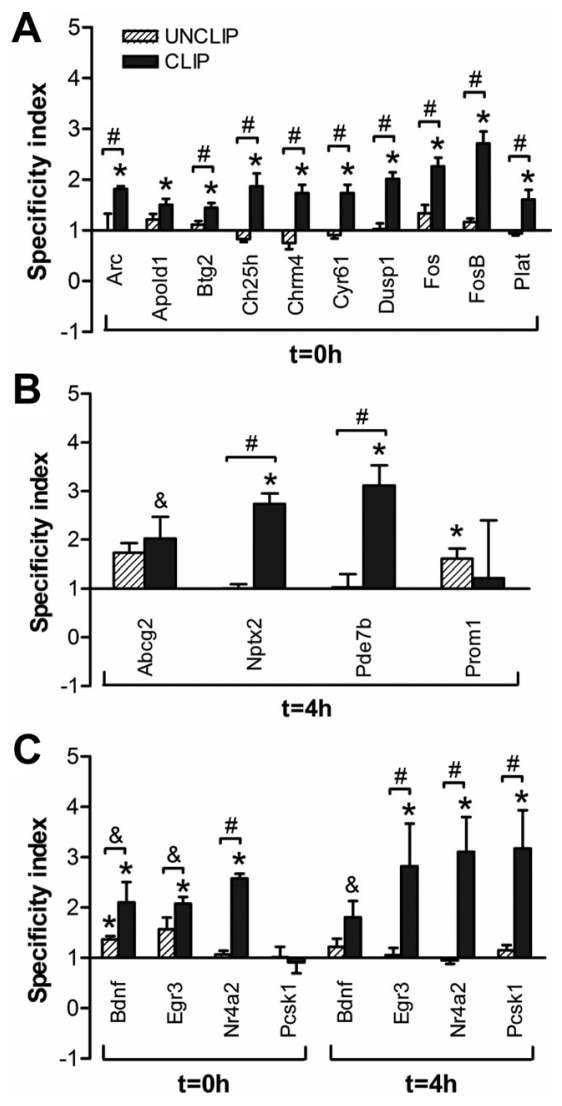

Figure 8. Specificity index showing the right/left ratio of activation in the two hemispheres of UNCLIP and CLIP groups. A specificity index was calculated, based on qPCR data, to explore the degree of activation of the genes selected for $q P C R$ validation in right $(R)$ versus left $(L)$ barrel cortices (for details, see Materials and Methods). In CLIP animals, if the index is higher than 1, activation is higher in spared (R) than in deprived (L) cortex. In UNCLIP animals, the specificity index quantifies hemispheric differences in the absence of clipping. Shown are the results of this index for genes specifically regulated after EE at $t=0 \mathrm{~h}(\boldsymbol{A}), t=4 \mathrm{~h}(\boldsymbol{B})$, or both time points $(\boldsymbol{C})$ (bottom). Bars represent average specificity index values \pm SEM. ${ }^{*}$ represents values significantly higher than 1 (one-sample $t$ test, reference value $1, p \leq 0.05$ ). \# represents significant differences between UNCLIP and CLIP groups ( $p \leq 0.05$, Student's $t$ test). Marginally significant differences are indicated by $\&$ symbol $(0.05<p \leq 0.1)$.

changes in expression determined by qPCR were the same as those found by microarray analysis and were similar between UNCLIP and CLIP groups. Indeed, we observed for a number of genes significant upregulation after EE at $t=0 \mathrm{~h}$ (Fig. 5, Arc, Apold1, Btg2, Ch25h, Chrm4, Cyr61, Dusp1, Fos, FosB, and Plat), at $t=4 \mathrm{~h}$ (Fig. 6, Nptx2 and phosphodiesterase 7B, Pde7b), or at both time points (Fig. 7, Bdnf, Egr3, Nr4a2, and Pcsk1) and significant downregulation at $t=4 \mathrm{~h}$ (Fig. 6, ABC transporter G2, Abcg2) (two-way ANOVA, followed by SNK post hoc tests, $p \leq$ 0.05). Only prominin 1 (Fig. 6, Prom 1 ), which was significantly downregulated at $t=4 \mathrm{~h}$ in UNCLIP animals, did not show significant differences in CLIP animals. Importantly, when compared with UNCLIP animals, EE-induced changes in gene expression in CLIP groups were more prominent in the spared ( $\mathrm{R}$ side) than in the deprived (L side) barrel cortex (Student's $t$ test, $p \leq 0.05$ ). However, for most genes, there was residual activation in the deprived side (when comparing $\mathrm{L}$ side of EE animals with respect to CTR animals, Student's $t$ test, $p \leq 0.05$ ). To quantify and statistically test the specificity of the effects in the spared side, we computed a specificity index for each gene. The index was defined as the ratio of the difference between EE and CTR expression levels in spared versus deprived side (Fig. 8). As expected, in 

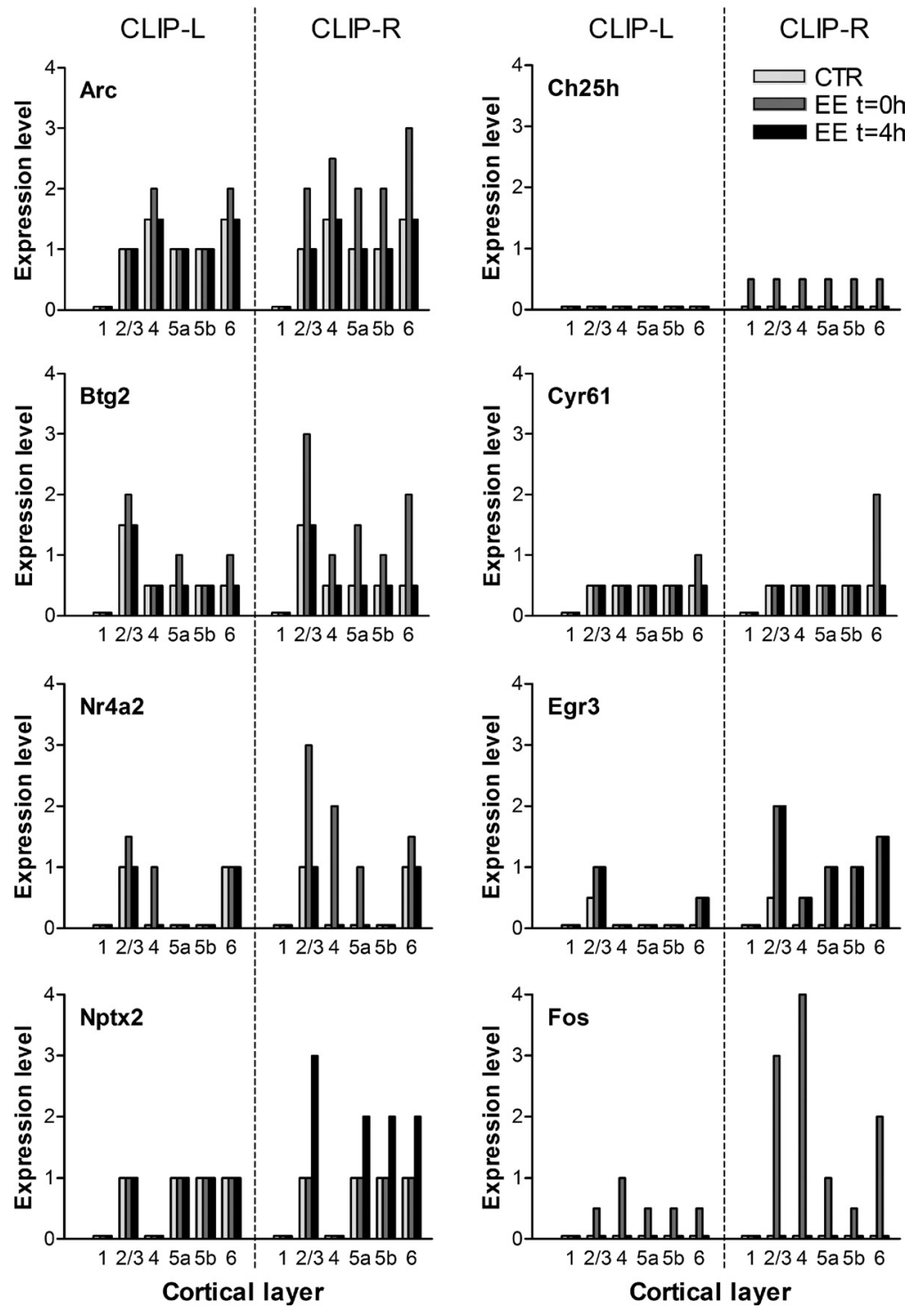

Figure 9. EE-induced layer-specific differential gene expression in the rat barrel cortex of CLIP groups. In situ hybridization analysis showing expression levels of selected genes in the barrel cortex, namely Arc, Btg2, Ch25h, Cyr61, Egr3, Fos, Nptx2, and $\mathrm{Nr} 4 \mathrm{a} 2$. Expression levels were evaluated in CLIP animals, under CTR, EE $t=0 \mathrm{~h}$, and EE $t=4 \mathrm{~h}$ conditions. The analysis was performed separately for left ( $L$, deprived) and right ( $R$, spared) barrel cortices. Note that the expression levels in the $R$ barrel cortex were similar as in UNCLIP animals and that $L$ barrel cortex only displayed residual activation.

CLIP groups, the specificity index was significantly higher than 1 for most genes tested (Student's one-sample $t$ test, reference value $1, p \leq 0.05$ ) (Fig. 8), indicating that in these groups the degree of activation in the spared side was substantially higher than in the deprived side. Similar results were found by in situ hybridization, showing only residual activation in the deprived side and prominent activation in the spared side (Fig. 9). These observations support the view that EE-induced changes in gene expression observed by microarray analysis at the level of the barrel cortex are specific for changes in sensory processing and do not merely reflect general changes in cortical activity.

\section{Discussion}

Using microarray mRNA expression profiling, we have provided a comprehensive view on the genes induced in the adult rat barrel cortex by sensory experience. The involvement of these genes in the processing of somatosensory information was supported by studying selected genes at a cellular (cortical layer) level and val- idating the results in deprived versus spared barrel cortices of whisker-clipped animals. Differentially expressed genes are involved in metabolic processes, regulation of transcription, and intracellular cascades such as PDGF and MAPK signaling pathways, but also in the regulation of synaptic plasticity and blood vessel morphogenesis. This is the first time that a genomewide study is applied at the level of the barrel cortex. Remarkably, the genes found to be differentially expressed in our study hardly overlap with those found by microarray analysis of whole cortex of adult EE-exposed mice (Rampon et al., 2000), possibly as a result of differences in experimental design (e.g., stress levels, length of EE exposure, timing of when the animals were killed, tissue and species used). Interestingly, some genes from our study do overlap with genes known to be regulated by sensory experience in rodent barrel cortex, such as $B d n f$, Crem, Egr1, Fos, FosB, and JunB (Rocamora et al., 1996; Pinaud et al., 2006). Our results also overlap, at least partly, with other genomewide studies in related models of experience-induced plasticity. For instance, in the visual cortex, a $4 \mathrm{~d}$ mononuclear deprivation at the peak of the critical period induced differential expression of genes also found in our dataset, namely Bdnf, Btg2, FosB, Insig1, Nptx2, and Pdgfb (Tropea et al., 2006). Strikingly, in the same model, a set of genes (Bdnf, Dusp1, Dusp6, Egr1, Egr2, Fos, FosB, Gadd45b, Ier2, JunB, and Nr4a1) is regulated independently of the developmental stage (Majdan and Shatz, 2006), and in the barrel cortex, we found that these MAPK signaling pathway components were also regulated by experience. Moreover, during singing behavior, some of these genes were also differentially expressed in the songbird brain (Wada et al., 2006; Dong et al., 2009), supporting their involvement in experience-dependent plasticity in the non-mammalian brain as well.

By studying gene expression at the level of the barrel cortex and validating the results by combining EE with whisker clipping, showing strong EE-induced mRNA expression in spared barrel cortex (contralateral to clipping), we have obtained information on genes involved in the processing of somatosensory input. However, although to a much smaller extent, differential expression was still observed in deprived barrel cortex (ipsilateral to clipping), suggesting residual processing of somatosensory input in the deprived hemisphere. This could be attributable to several reasons. First, because whisker clipping leaves the whisker follicles intact, whiskers may still have transmitted sensory information during attempted whisking attributable to follicle stimulation. Second, passive activation attributable to skin contact may have effects similar to passive whisker deflections, which are known to cause postsynaptic potentials in the ipsilateral barrel, although with smaller amplitudes and longer latencies (Manns et al., 2004). Third, it is possible that activation from the spared cortex can 
spread to the contralateral side via callosal projections. The paralemniscal pathway has strong interhemispheric connections (Li and Ebner, 2006), conveys information about the temporal frequency of whisker movements (Ahissar et al., 2000), and is involved in the sensorimotor control of whisker movement by providing reference signals during object recognition ( $\mathrm{Yu}$ et al., 2006). Such information could be relevant in an EE in which several novel stimuli are present, possibly leading to a highly active paralemniscal pathway and the observed residual processing.

Sensory experiences and the resulting synaptic activity are critical for the shaping of neuronal networks in the barrel cortex. Several processes, including dendritic branching, synaptogenesis, maturation, and elimination of synapses, lie at the base of this shaping (Flavell and Greenberg, 2008). Transcription precedes experience-dependent plasticity by regulating the expression of several downstream genes that subsequently modulate synaptic properties. In fact, many of the transcription factor genes detected in our microarray analysis have been linked previously to synaptic plasticity, in either the barrel cortex or other brain regions. For instance, $\mathrm{Btg} 2$ is involved in neuronal differentiation (Bradbury et al., 1991) and plays a crucial role in contextual memory (Farioli-Vecchioli et al., 2008, 2009). The upregulation of Crem during EE confirms previous observations, also in barrel cortex (Bisler et al., 2002), supporting its key role in neuronal plasticity (Mioduszewska et al., 2003). Fos and Jun induce expression of $B d n f$ (Zhang et al., 2002), one of the pivotal molecules in neuronal plasticity (Greenberg et al., 2009). In the barrel cortex, Bdnf regulates the balance between excitatory and inhibitory neurotransmitter systems (Genoud et al., 2004) and was also upregulated in our study, together with two of its processing enzymes, Pcsk1 (Seidah and Chrétien, 1999) and Plat (Pang et al., 2004). Interestingly, Bdnf activation increases expression of Egr3 (Roberts et al., 2006), which is involved in short-term memory (Poirier et al., 2008). Egr3 has been shown to induce expression of Arc, which is essential for long-term potentiation (LTP) persistence (Li et al., 2005). EE upregulates Arc expression in rat barrel cortex and hippocampus (Ramírez-Amaya et al., 2005). Finally, all members of the inducible orphan nuclear receptor family of transcription factors (Nr4a1, Nr4a2, and Nr4a3) were also upregulated during EE. This, together with their implication in neuronal development (Perlmann and Wallén-Mackenzie, 2004) and responsiveness to depolarization (Lam et al., 2010), suggests a key role for these transcription factors in experience-dependent plasticity.

Apart from transcription factors, the MAPK and PDGF receptor signaling pathways were also significantly regulated during enrichment, as evidenced by the GO analysis. Activation of the MAPK pathway by glutamate receptors has been associated with synaptic plasticity (Wang et al., 2007). The phosphatases Dusp1 and Dusp6 were both upregulated by EE; Dusp1 targets the MAPK pathway (Farooq and Zhou, 2004) and is in turn inhibited by Dusp6 (Vogt et al., 2005). Given that a short activation of the MAPK pathway is enough to ensure LTP (Wang et al., 2007), expression of these phosphatases probably serves to fine tune the activation of this signaling cascade and overcome detrimental effects of sustained cellular activation. As to the PDGF-B receptor signaling pathway, recent studies suggest that PDGF-B plays a role in regulating NMDA receptor excitability (Egawa-Tsuzuki et al., 2004) and that PDGF-B is also able to induce Arc expression (Peng et al., 2010), linking this pathway to neuronal plasticity.

An intriguing finding in our study was the differential expression of genes related to blood vessel morphogenesis, namely
Cyr61 and Apold1. Cyr61 is important for extracellular matrix production (Chen and $\mathrm{Du}, 2007$ ) and is under the control of muscarinic acetylcholine receptor (Chrm) signaling in cortical neurons (Albrecht et al., 2000); interestingly, Chrm4 was also upregulated in our study. The possible reorganization of neural networks in barrel cortex may increase the need for energy supply and thus for the formation of novel blood vessels in which Cyr61 could be of central importance. This could hold for Apold1 as well, which regulates the differentiation of brain endothelial cells and has been shown to respond to seizures and hypoxia in brain vasculature (Regard et al., 2004). Genes involved in cholesterol biosynthesis, shown to be expressed in neuronal cells (Valdez et al., 2010), such as Ch25h or Hmgcr, were also differentially expressed. The link between cholesterol turnover, LTP, and learning has been established previously (Kotti et al., 2006), and more recently the activity of presynaptic protein kinases has been found to be sensitive to changes in membrane cholesterol content (Smith et al., 2010).

Finally, although not clearly overrepresented in a particular functional category, Ptgs 2 and Nptx2 have also been linked previously to neuronal plasticity. For instance, Ptgs 2 plays a crucial role in the modulation of hippocampal synaptic transmission and plasticity by regulating prostaglandin signaling (Sang and Chen, 2006). Nptx2 overexpression induces the formation of excitatory synapses (O'Brien et al., 1999) and clustering of AMPA receptors in vitro (Fox and Umemori, 2006).

In addition to knowledge about their functional background, knowing the timing and cellular expression patterns of the differentially expressed genes is crucial to understand their role in S1 plasticity. Our detailed analysis of selected genes indicates that both input (layer 4 ) and output layers are activated early after EE. For instance, at $t=0 \mathrm{~h}, \mathrm{Fos}$ and $\mathrm{Nr} 4 \mathrm{a} 2$ are activated in input and output layers, whereas Btg2 is primarily activated in output layers. In contrast, at later time points, mainly output layers are activated, as evidenced from the Egr3 and Nptx2 expression patterns at $t=4 \mathrm{~h}$. These findings suggest that initial gene activation would reflect changes in presynaptic and postsynaptic neurons in S1, whereas later in time it would reflect postsynaptic changes. Interestingly, changes in layer $2 / 3$, the most plastic layer in adult barrel cortex (Fox, 2002), seem to be more long lasting, linking gene expression to neuronal plasticity.

In summary, we show that, in vivo, somatosensory processing in the rat barrel cortex activates a wide variety of genes in a timeand layer-specific manner. Thus, the present data provide a solid experimental framework for future genetic, electrophysiological, and imaging studies that will give insight into the mechanisms underlying experience-dependent reorganization of sensory systems.

\section{References}

Ahissar E, Sosnik R, Haidarliu S (2000) Transformation from temporal to rate coding in a somatosensory thalamocortical pathway. Nature 406:302-306.

Albrecht C, von Der Kammer H, Mayhaus M, Klaudiny J, Schweizer M, Nitsch RM (2000) Muscarinic acetylcholine receptors induce the expression of the immediate early growth regulatory gene CYR61. J Biol Chem 275:28929-28936.

Aronoff R, Petersen CC (2008) Layer, column and cell-type specific genetic manipulation in mouse barrel cortex. Front Neurosci 2:64-71.

Barth AL, McKenna M, Glazewski S, Hill P, Impey S, Storm D, Fox K (2000) Upregulation of cAMP response element-mediated gene expression during experience-dependent plasticity in adult neocortex. J Neurosci 20:4206-4216.

Bisler S, Schleicher A, Gass P, Stehle JH, Zilles K, Staiger JF (2002) Expression of c-Fos, ICER, Krox-24 and JunB in the whisker-to-barrel pathway 
of rats: time course of induction upon whisker stimulation by tactile exploration of an enriched environment. J Chem Neuroanat 23:187-198.

Bonefeld BE, Elfving B, Wegener G (2008) Reference genes for normalization: a study of rat brain tissue. Synapse 62:302-309.

Bradbury A, Possenti R, Shooter EM, Tirone F (1991) Molecular cloning of PC3, a putatively secreted protein whose mRNA is induced by nerve growth factor and depolarization. Proc Natl Acad Sci U S A 88:3353-3357.

Brecht M (2007) Barrel cortex and whisker-mediated behaviors. Curr Opin Neurobiol 17:408-416.

Brecht M, Fee MS, Garaschuk O, Helmchen F, Margrie TW, Svoboda K, Osten P (2004) Novel approaches to monitor and manipulate single neurons in vivo. J Neurosci 24:9223-9227.

Chen Y, Du XY (2007) Functional properties and intracellular signaling of CCN1/Cyr61. J Cell Biochem 100:1337-1345.

Curran T, Morgan JI (1995) Fos: an immediate-early transcription factor in neurons. J Neurobiol 26:403-412.

Dennis G Jr, Sherman BT, Hosack DA, Yang J, Gao W, Lane HC, Lempicki RA (2003) DAVID: database for annotation, visualization, and integrated discovery. Genome Biol 4:P3.

Diamond ME, von Heimendahl M, Knutsen PM, Kleinfeld D, Ahissar E (2008) "Where" and "what" in the whisker sensorimotor system. Nat Rev Neurosci [Erratum (2008) 9:709] 9:601-612.

Dong S, Replogle KL, Hasadsri L, Imai BS, Yau PM, Rodriguez-Zas S, Southey BR, Sweedler JV, Clayton DF (2009) Discrete molecular states in the brain accompany changing responses to a vocal signal. Proc Natl Acad Sci U S A 106:11364-11369.

Egawa-Tsuzuki T, Ohno M, Tanaka N, Takeuchi Y, Uramoto H, Faigle R, Funa K, Ishii Y, Sasahara M (2004) The PDGF B-chain is involved in the ontogenic susceptibility of the developing rat brain to NMDA toxicity. Exp Neurol 186:89-98.

Farioli-Vecchioli S, Saraulli D, Costanzi M, Pacioni S, Cinà I, Aceti M, Micheli L, Bacci A, Cestari V, Tirone F (2008) The timing of differentiation of adult hippocampal neurons is crucial for spatial memory. PLoS Biol 6:e246.

Farioli-Vecchioli S, Saraulli D, Costanzi M, Leonardi L, Cinà I, Micheli L, Nutini M, Longone P, Oh SP, Cestari V, Tirone F (2009) Impaired terminal differentiation of hippocampal granule neurons and defective contextual memory in PC3/Tis21 knockout mice. PloS One 4:e8339.

Farooq A, Zhou MM (2004) Structure and regulation of MAPK phosphatases. Cell Signal 16:769-779.

Feldman DE, Brecht M (2005) Map plasticity in somatosensory cortex. Science 310:810-815.

Filipkowski RK, Rydz M, Kaczmarek L (2001) Expression of c-Fos, Fos B, Jun B, and Zif268 transcription factor proteins in rat barrel cortex following apomorphine-evoked whisking behavior. Neuroscience 106:679-688.

Flavell SW, Greenberg ME (2008) Signaling mechanisms linking neuronal activity to gene expression and plasticity of the nervous system. Annu Rev Neurosci 31:563-590.

Fox K (2002) Anatomical pathways and molecular mechanisms for plasticity in the barrel cortex. Neuroscience 111:799-814.

Fox MA, Umemori H (2006) Seeking long-term relationship: axon and target communicate to organize synaptic differentiation. J Neurochem 97:1215-1231

Genoud C, Knott GW, Sakata K, Lu B, Welker E (2004) Altered synapse formation in the adult somatosensory cortex of brain-derived neurotrophic factor heterozygote mice. J Neurosci 24:2394-2400.

Genoud C, Quairiaux C, Steiner P, Hirling H, Welker E, Knott GW (2006) Plasticity of astrocytic coverage and glutamate transporter expression in adult mouse cortex. PLoS Biol 4:e343.

Greenberg ME, Xu B, Lu B, Hempstead BL (2009) New insights in the biology of BDNF synthesis and release: implications in CNS function. J Neurosci 29:12764-12767.

Harwell C, Burbach B, Svoboda K, Nedivi E (2005) Regulation of cpg15 expression during single whisker experience in the barrel cortex of adult mice. J Neurobiol 65:85-96.

Huang da W, Sherman BT, Lempicki RA (2009) Systematic and integrative analysis of large gene lists using DAVID bioinformatics resources. Nat Protoc 4:44-57.

Huber D, Petreanu L, Ghitani N, Ranade S, Hromádka T, Mainen Z, Svoboda K (2008) Sparse optical microstimulation in barrel cortex drives learned behaviour in freely moving mice. Nature 451:61-64.
Ishibashi H (2002) Increased synaptophysin expression through whisker stimulation in rat. Cell Mol Neurobiol 22:191-195.

Knott G, Holtmaat A (2008) Dendritic spine plasticity-current understanding from in vivo studies. Brain Res Rev 58:282-289.

Korosi A, Veening JG, Kozicz T, Henckens M, Dederen J, Groenink L, van der Gugten J, Olivier B, Roubos EW (2006) Distribution and expression of CRF receptor 1 and 2 mRNAs in the CRF over-expressing mouse brain. Brain Res 1072:46-54.

Kotti TJ, Ramirez DM, Pfeiffer BE, Huber KM, Russell DW (2006) Brain cholesterol turnover required for geranylgeraniol production and learning in mice. Proc Natl Acad Sci U S A 103:3869-3874.

Lam BY, Zhang W, Ng DC, Maruthappu M, Roderick HL, Chawla S (2010) CREB-dependent Nur77 induction following depolarization in PC12 cells and neurons is modulated by MEF2 transcription factors. J Neurochem 112:1065-1073

Lein ES, Hawrylycz MJ, Ao N, Ayres M, Bensinger A, Bernard A, Boe AF, Boguski MS, Brockway KS, Byrnes EJ, Chen L, Chen L, Chen TM, Chin MC, Chong J, Crook BE, Czaplinska A, Dang CN, Datta S, Dee NR, et al. (2007) Genome-wide atlas of gene expression in the adult mouse brain. Nature 445:168-176.

Li L, Ebner FF (2006) Balancing bilateral sensory activity: callosal processing modulates sensory transmission through the contralateral thalamus by altering the response threshold. Exp Brain Res 172:397-415.

Li L, Carter J, Gao X, Whitehead J, Tourtellotte WG (2005) The neuroplasticityassociated arc gene is a direct transcriptional target of early growth response (Egr) transcription factors. Mol Cell Biol 25:10286-10300.

Majdan M, Shatz CJ (2006) Effects of visual experience on activitydependent gene regulation in cortex. Nat Neurosci 9:650-659.

Manns ID, Sakmann B, Brecht M (2004) Sub- and suprathreshold receptive field properties of pyramidal neurones in layers $5 \mathrm{~A}$ and $5 \mathrm{~B}$ of rat somatosensory barrel cortex. J Physiol 556:601-622.

Mioduszewska B, Jaworski J, Kaczmarek L (2003) Inducible cAMP early repressor (ICER) in the nervous system: a transcriptional regulator of neuronal plasticity and programmed cell death. J Neurochem 87:1313-1320.

O’Brien RJ, Xu D, Petralia RS, Steward O, Huganir RL, Worley P (1999) Synaptic clustering of AMPA receptors by the extracellular immediateearly gene product Narp. Neuron 23:309-323.

Pang PT, Teng HK, Zaitsev E, Woo NT, Sakata K, Zhen S, Teng KK, Yung WH, Hempstead BL, Lu B (2004) Cleavage of proBDNF by tPA/plasmin is essential for long-term hippocampal plasticity. Science 306:487-491.

Paxinos G, Watson C (1998) The rat brain in stereotaxic coordinates. San Diego: Academic.

Peng F, Yao H, Bai X, Zhu X, Reiner BC, Beazely M, Funa K, Xiong H, Buch S (2010) Platelet-derived growth factor-mediated induction of the synaptic plasticity gene Arc/Arg3.1. J Biol Chem 285:21615-21624.

Perlmann T, Wallén-Mackenzie A (2004) Nurr1, an orphan nuclear receptor with essential functions in developing dopamine cells. Cell Tissue Res 318:45-52.

Petersen CC (2007) The functional organization of the barrel cortex. Neuron 56:339-355.

Petersen CC (2009) Genetic manipulation, whole-cell recordings and functional imaging of the sensorimotor cortex of behaving mice. Acta Physiol (Oxf) 195:91-99.

Petreanu L, Mao T, Sternson SM, Svoboda K (2009) The subcellular organization of neocortical excitatory connections. Nature 457:1142-1145.

Pinaud R, Filipkowski RK, Fortes AF, Tremere LA (2006) Immediate early gene expression in the primary somatosensory cortex: focus on the barrel cortex. In: Immediate early genes in sensory processing, cognitive performance and neurological disorders (Pinaud R, Tremere LA, eds), pp 7392. New York: Springer Science + Business Media.

Poirier R, Cheval H, Mailhes C, Garel S, Charnay P, Davis S, Laroche S (2008) Distinct functions of egr gene family members in cognitive processes. Front Neurosci 2:47-55.

Polley DB, Kvasnák E, Frostig RD (2004) Naturalistic experience transforms sensory maps in the adult cortex of caged animals. Nature 429:67-71.

Ramírez-Amaya V, Vazdarjanova A, Mikhael D, Rosi S, Worley PF, Barnes CA (2005) Spatial exploration-induced Arc mRNA and protein expression: evidence for selective, network-specific reactivation. J Neurosci 25:1761-1768.

Rampon C, Jiang CH, Dong H, Tang YP, Lockhart DJ, Schultz PG, Tsien JZ, 
Hu Y (2000) Effects of environmental enrichment on gene expression in the brain. Proc Natl Acad Sci U S A 97:12880-12884.

Regard JB, Scheek S, Borbiev T, Lanahan AA, Schneider A, Demetriades AM, Hiemisch H, Barnes CA, Verin AD, Worley PF (2004) Verge: a novel vascular early response gene. J Neurosci 24:4092-4103.

Roberts DS, Hu Y, Lund IV, Brooks-Kayal AR, Russek SJ (2006) Brainderived neurotrophic factor (BDNF)-induced synthesis of early growth response factor 3 (Egr3) controls the levels of type A GABA receptor alpha 4 subunits in hippocampal neurons. J Biol Chem 281:29431-29435.

Rocamora N, Welker E, Pascual M, Soriano E (1996) Upregulation of BDNF mRNA expression in the barrel cortex of adult mice after sensory stimulation. J Neurosci 16:4411-4419.

Sang N, Chen C (2006) Lipid signaling and synaptic plasticity. Neuroscientist 12:425-434.

Schaeren-Wiemers N, Gerfin-Moser A (1993) A single protocol to detect transcripts of various types and expression levels in neural tissue and cultured cells: in situ hybridization using digoxigenin-labelled cRNA probes. Histochemistry 100:431-440.

Schubert D, Kötter R, Staiger JF (2007) Mapping functional connectivity in barrel-related columns reveals layer- and cell type-specific microcircuits. Brain Struct Funct 212:107-119.

Seidah NG, Chrétien M (1999) Proprotein and prohormone convertases: a family of subtilases generating diverse bioactive polypeptides. Brain Res 848:45-62.

Sheng M, Greenberg ME (1990) The regulation and function of c-fos and other immediate early genes in the nervous system. Neuron 4:477-485.

Smith AJ, Sugita S, Charlton MP (2010) Cholesterol-dependent kinase activity regulates transmitter release from cerebellar synapses. J Neurosci 30:6116-6121.

Spruijt BM, van Hooff JA, Gispen WH (1992) Ethology and neurobiology of grooming behavior. Physiol Rev 72:825-852.

Tropea D, Kreiman G, Lyckman A, Mukherjee S, Yu H, Horng S, Sur M
(2006) Gene expression changes and molecular pathways mediating activity-dependent plasticity in visual cortex. Nat Neurosci 9:660-668.

Tusher VG, Tibshirani R, Chu G (2001) Significance analysis of microarrays applied to the ionizing radiation response. Proc Natl Acad Sci U S A 98:5116-5121.

Valdez CM, Smith MA, Perry G, Phelix CF, Santamaria F (2010) Cholesterol homeostasis markers are localized to mouse hippocampal pyramidal and granule layers. Hippocampus 20:902-905.

Vandesompele J, De Preter K, Pattyn F, Poppe B, Van Roy N, De Paepe A, Speleman F (2002) Accurate normalization of real-time quantitative RT-PCR data by geometric averaging of multiple internal control genes. Genome Biol 3:RESEARCH0034.

Vogt A, Tamewitz A, Skoko J, Sikorski RP, Giuliano KA, Lazo JS (2005) The benzo[c]phenanthridine alkaloid, sanguinarine, is a selective, cell-active inhibitor of mitogen-activated protein kinase phosphatase-1. J Biol Chem 280:19078-19086.

Wada K, Howard JT, McConnell P, Whitney O, Lints T, Rivas MV, Horita H, Patterson MA, White SA, Scharff C, Haesler S, Zhao S, Sakaguchi H, Hagiwara M, Shiraki T, Hirozane-Kishikawa T, Skene P, Hayashizaki Y, Carninci P, Jarvis ED (2006) A molecular neuroethological approach for identifying and characterizing a cascade of behaviorally regulated genes. Proc Natl Acad Sci U S A 103:15212-15217.

Wang JQ, Fibuch EE, Mao L (2007) Regulation of mitogen-activated protein kinases by glutamate receptors. J Neurochem 100:1-11.

Woolsey TA, Van der Loos H (1970) The structural organization of layer IV in the somatosensory region (SI) of mouse cerebral cortex. The description of a cortical field composed of discrete cytoarchitectonic units. Brain Res 17:205-242.

Yu C, Derdikman D, Haidarliu S, Ahissar E (2006) Parallel thalamic pathways for whisking and touch signals in the rat. PLoS Biol 4:e124.

Zhang J, Zhang D, McQuade JS, Behbehani M, Tsien JZ, Xu M (2002) c-fos regulates neuronal excitability and survival. Nat Genet 30:416-420. 